\title{
Artificial (Pseudo)peptides for Molecular Recognition and Catalysis
}

\author{
Leonard J. Prins and Paolo Scrimin
}

1.1

Introduction

This chapter focuses on recognition and catalytic processes in which artificial (pseudo)peptide sequences, which can be very short, play a decisive role. The enormous amount of literature related to this topic is far beyond the scope of a single chapter, and, therefore, we intend to emphasize concepts and breakthroughs by using representative examples. Obviously, the reason for the interest in the role of (pseudo)peptides in molecular recognition and catalysis is the fact that polypeptides, e.g. proteins, play a crucial role in practically all biologically relevant processes. An incredible number of recognition events is of key importance for the occurrence of life. The origin of biological recognition is the tertiary structure of proteins, which is marvelously determined by conformationally well-defined secondary structures such as $\alpha$-helices, $\beta$ sheets, coiled coils, etc. These locally structured units give order to the overall system, positioning functional groups precisely in three-dimensional space, thus creating an active site where recognition takes place. Molecular recognition is especially crucial in the functioning of enzymes. To accomplish its powerful tasks an enzyme first needs to recognize the substrate and, subsequently, in the course of its chemical transformation, also the intermediate transition state that lies on the reaction pathway toward the product. These impressive results in Nature form an almost infinite source of inspiration for the chemist, not only to mimic natural functions but also to modify them and apply them in unnatural situations.

In this chapter we will discuss advances that have been made in our learning process from Nature and, more specifically, show how chemists are able to mimic natural functions using artificial synthetic molecules. First, we will focus on the biomolecular recognition of oligonucleotides (DNA/RNA) and protein surfaces by artificial oligopeptides. Next, we will show that chemists have learned to control the secondary structure of (pseudo)peptides and that specific (catalytic) functions can be introduced at will. Finally, we will conclude with a brief overview of the selection of (pseudo)peptide catalysts by a combinatorial approach. 
1.2

Recognition of Biological Targets by Pseudo-peptides

\subsection{1}

\section{Introduction}

In all organisms, nucleic acids are responsible for the storage and transfer of genetic information. With the aim of curing gene-originated diseases, artificial molecules that can interact with DNA and RNA are of utmost interest. In this section we will discuss the current state of two major classes of pseudo-peptides that are currently under intense investigation - polyamides that bind in the minor groove of DNA and peptide nucleic acids (PNA). Both classes of compounds are inspired by naturally occurring analogs. The high synthetic accessibility and the ease with which chemical functionality can be introduced illustrate the high potential of artificial pseudo-peptides. In addition, their high biostability has enabled successful applications in both in-vitro and in-vivo studies. The limiting properties of these compounds will also be addressed.

Another way of interfering with biological processes is to obstruct the activity of proteins themselves. Pseudo-peptides that inhibit the formation of protein-protein complexes via competitive binding to the dimerization interface will be discussed. Selected examples will be given that clearly illustrate the strong increase in activity when amino acids present in a wild-type peptide sequence are replaced by artificial amino acids.

\subsection{2}

\section{Polyamides as Sequence-specific DNA-minor-groove Binders}

The discovery of the mode of interaction between the natural compounds distamycin and netropsin and the minor groove of DNA has been the impetus for the development of a set of chemical rules that determine how the minor groove of DNA can be addressed sequence-specifically [1]. NMR and X-ray spectroscopy showed that distamycin binds to A,T-tracts 4 to 5 base pairs in length either in a 1:1 or 2:1 fashion, depending on the concentration (Fig. 1.1) [2, 3]. It was then immediately realized by the groups of Dickerson, Lown, and Dervan that the minor groove of DNA is chemically addressable and, importantly, that chemical modifications of the natural compounds should, in theory, provide an entry to complementary molecules for each desirable sequence $[4,5]$.

\subsubsection{Pairing Rules}

The minor groove of DNA is chemically characterized by several properties. First, the specific positions of hydrogen-bond donor and acceptor sites on each Watson-Crick base pair, as depicted schematically in Fig. 1.2. Next, the molecular shape of the minor groove in terms of specific steric size, such as the exocyclic $\mathrm{NH}_{2}$ guanine. Finally, an important property is the curvature of the double stranded DNA helix. Having 

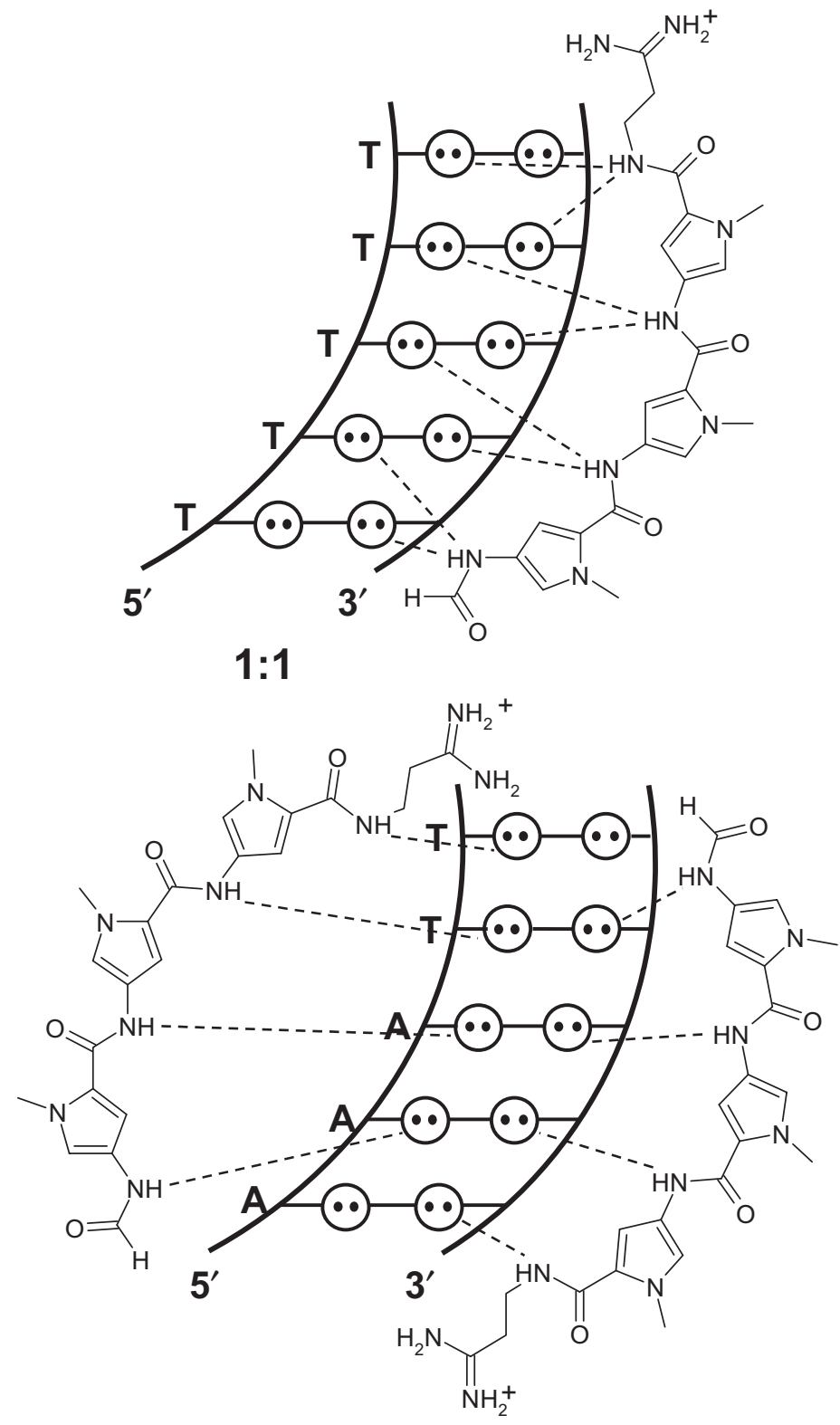

1:2

Figure 1.1 Observed binding modes of distamycin to DNA (1:1 and 1:2 complexes). The dotted circles represent the lone pairs of $\mathrm{N}(3)$ of purines and $\mathrm{O}(2)$ of pyrimidines in the minor groove. The dotted lines represent hydrogen bonds between distamycin and DNA. 
<smiles></smiles>

\section{G- $-(H)-H c$}

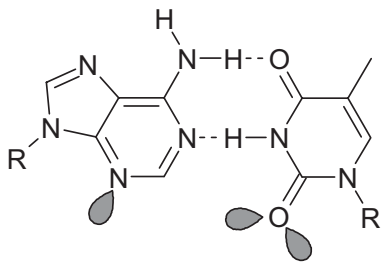

\section{$\mathrm{A} \odot \odot-\odot \mathrm{T}$}

Figure 1.2 Hydrogen-bond donors and acceptors present in the minor groove of ds DNA for each of the four Watson-Crick base pairs. Lone pairs are indicated by shaded orbitals

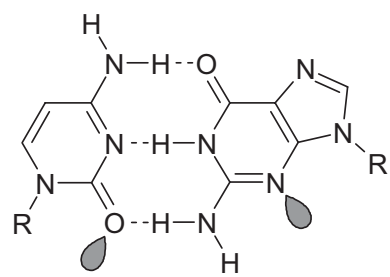

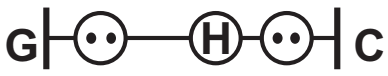

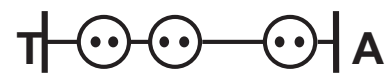

and $\mathrm{R}$ represents the sugar-phosphate backbone. In the schematic representations circles with dots are hydrogen-bond acceptors and circles with $\mathrm{H}$ are hydrogen-bond donors.

these properties as a guideline, Dervan and coworkers have developed a series of fivemembered heterocycles that pairwise can recognize each of the four base pairs [6, 7]. These couples and their binding modes are schematically depicted in Fig. 1.3. To gain selectivity for a G,C over an A,T base pair, the pyrrole ring (Py) was substituted by an imidazole (Im), which forms an additional hydrogen-bond with the exocyclic $\mathrm{NH}_{2}$ of guanine, as confirmed by crystal structure analysis. In addition, replacement of the pyrrole $\mathrm{CH}$ for an $\mathrm{N}$ eliminates the steric clash of pyrrole and the exocyclic $\mathrm{NH}_{2}$ of guanine. The presence of an additional hydrogen-bond acceptor on thymine residues stimulated the synthesis of the $\mathrm{N}$-methyl-3-hydroxypyrrole ( $\mathrm{Hp}$ ) monomer, which contains an additional hydrogen-bond donor. Also, in this case, the complementary molecular shape between the cleft imposed by the thymine-O2 and the adenine-C2 and the bumpy -OH are important.

The selective binding to T,A over A,T base pairs (and, similarly, G,C over C,G) originates from the antiparallel binding of two polyamide strands in the minor groove of DNA. A key NMR spectroscopy study confirmed that an ImPyPy polyamide bound 


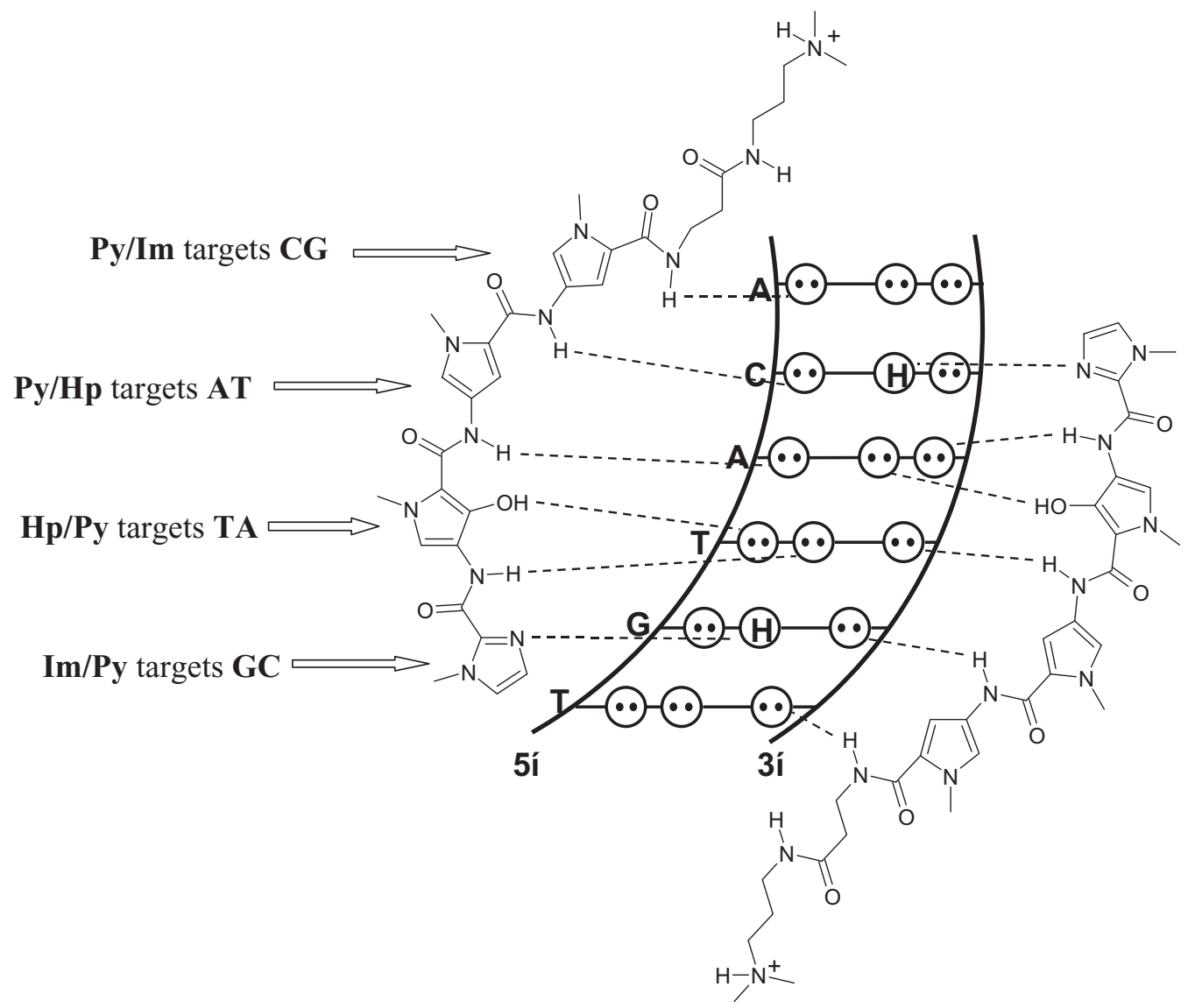

Figure 1.3 Pairing rules for dsDNA recognition by polyamides.

Py: pyrrole, Im: imidazole, Hp: hydroxypyrrole.

antiparallel in a 2:1 fashion to a 5'-WGWCW-3' sequence (W = A or T) with the polyamide oriented $\mathrm{N} \rightarrow \mathrm{C}$ with respect to the $5^{\prime} \rightarrow 3^{\prime}$ direction of the adjacent DNA strand.

Recently, the repertoire of the heterocycles used (Py, Im, and Hp) has been expanded to novel structures based on pyrazole, thiophene, and furan, to increase binding specificity and stability (the Hp monomer has limited stability in the presence of free acid or radicals) [8]. In addition, benzimidazole-based monomers (Ip and Hz) were incorporated in polyamides as alternatives for the dimeric subunits PyIm and PyHp, respectively $[9,10]$. DNase I footprinting revealed functionally similar behavior with regard to the parent compounds containing exclusively Py, Im, and $\mathrm{Hp}$ monomers. An important advantage is the chemical robustness of the benzimidazole monomer $\mathrm{Hz}$ relative to $\mathrm{Hp}$. 


\subsubsection{Binding Affinity and Selectivity}

The ternary complex composed of two three-ring structures, such as distamycin, and DNA is rather modest, for entropic reasons and because of the low number of hydrogen bonds involved. In an important step forward towards artificial DNA binders that can effectively compete with DNA-binding proteins, the carboxyl and amino termini of two polyamide chains were covalently connected via a $\gamma$-aminobutyric acid linker (Fig. 1.4a) [11]. A so-called hairpin polyamide composed of eight heterocycles was shown to bind to the complementary six-base-pair DNA sequence with an affinity constant of the order of $10^{10} \mathrm{M}^{-1}$. A single base-pair mismatch site induced a 10-100-fold drop in affinity. Importantly, the $\mathrm{N} \rightarrow \mathrm{C}$ orientation with respect to the $5^{\prime} \rightarrow 3^{\prime}$ direction of DNA is generally retained for these compounds. An additional tenfold increase in affinity was observed for a cyclic polyamide in which the two strands were covalently connected at both termini (Fig. 1.4b) [12]. The $\gamma$-turn has a preference for an A,T over a G,C base pair, presumably because of a steric clash between the aliphatic turn and the exocyclic amine of guanine. New polyamide structures that are covalently bridged via the heterocycle nitrogen atoms, either at the center (H-pin, Fig. 1.4c) or terminus (U-pin, Fig. 1.4d) have recently been prepared [13, 14]. The Upins resulted in a loss in affinity, because of the removal of two hydrogen bond donors, but were insensitive to the base pair adjacent to the turn. Cleverly, the H-pin polyamides were synthesized on a solid support using the Ru-catalyzed alkene metathesis reaction to connect the different polyamides. This approach enabled the rapid synthesis and screening of a series of polyamides with alkyl bridges differing in size $\left(\left(\mathrm{CH}_{2}\right)_{n}\right.$, with $n$ ranging from 4 to 8$)$; the optimum affinity and specificity was obtained for $n=6$.

In the gigabase-sized DNA database it is desirable to address sequences of 10-16 base pairs, because these occur much less frequently. Increasing the number of heterocycles in polyamides increases the sequence size that can be targeted, but only up to a certain limit. Studies revealed that the binding affinity is maximized at a contiguous ring number of 5 . For longer systems affinity drops because the different curvatures of polyamides and B-DNA starts to give energetically strongly unfavorable interactions. These problems can be partially overcome by replacing one (or more) of the pyrrole units by a more flexible $\beta$-alanine unit. In this way polyamides have been prepared that bind sequences as long as 11 base pairs with subnanomolar affinities [15]. Alternatively, two hairpin polyamides have been covalently connected either turn-to-turn or turn-to-tail and were shown to bind ten-base-pair sequences with impressive affinities in the order of $10^{12} \mathrm{M}^{-1}[16,17]$. It should be noted, however, that these high affinities come with rather low selectivity.

The potential of these molecules in controlling gene expression is extremely important; here are examples that illustrate this point. Because excellent reviews have appeared that cover in great detail all results obtained, we will limit ourselves to recent examples that illustrate well the different concepts. 

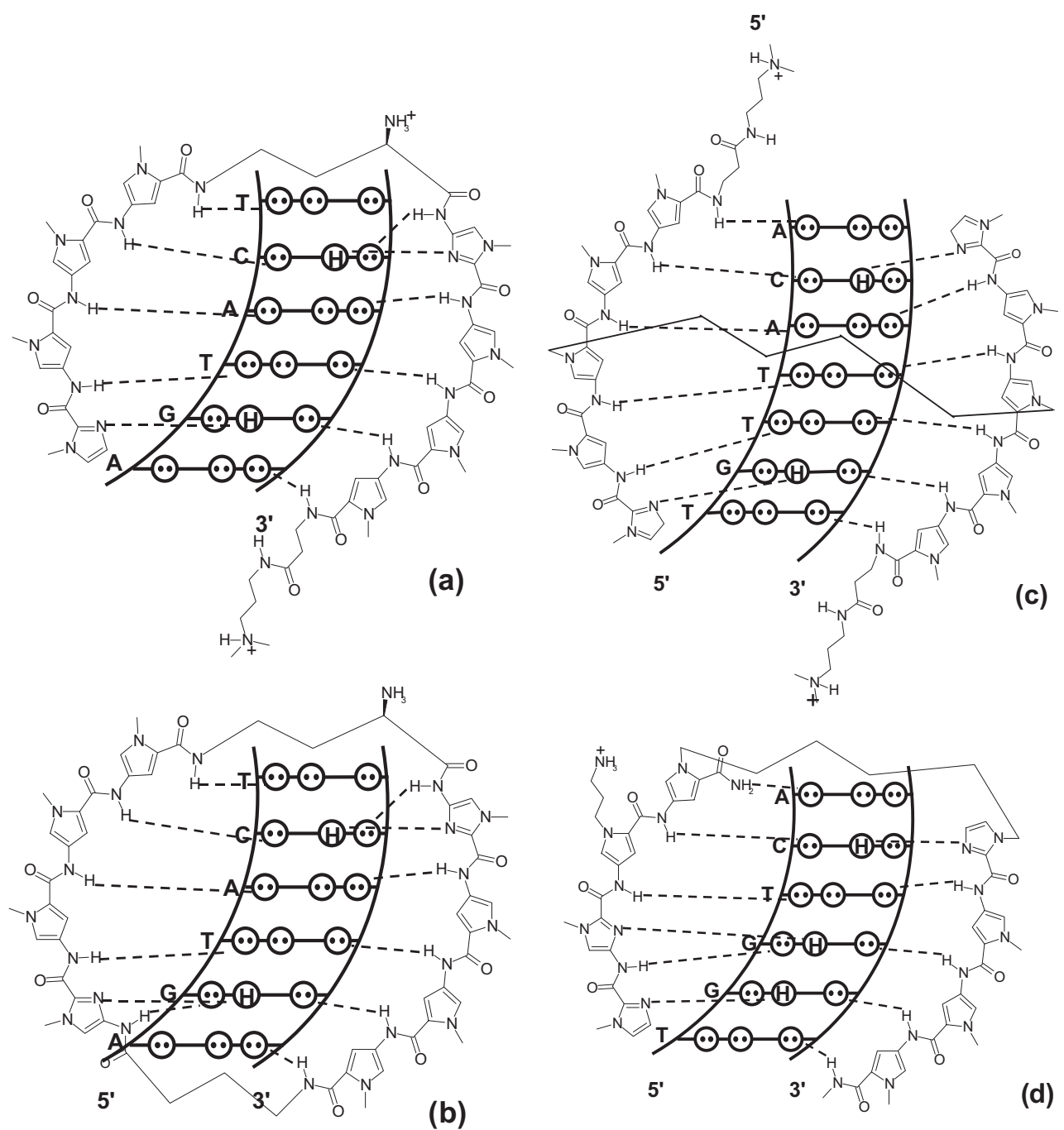

Figure 1.4 Strategies in polyamide design: (a) hairpin $\left(K_{\mathrm{a}} \approx 10^{11} \mathrm{M}^{-1}\right)$;

(b) cycle $\left(K_{\mathrm{a}} \approx 10^{11} \mathrm{M}^{-1}\right)$; (c) H-pin $\left(K_{\mathrm{a}} \approx 10^{10} \mathrm{M}^{-1}\right)$; (d) U-pin $\left(K_{\mathrm{a}} \approx 10^{9} \mathrm{M}^{-1}\right)$.

\subsubsection{DNA Detection}

The ability to detect double stranded DNA sequences, and single base-pair mismatches, is an extremely useful tool in the field of genetics. Most methods involve hybridization of single-stranded DNA by a complementary oligonucleotide probe, which carries a signaling moiety. These techniques, however, require denaturation of DNA. On the other hand, double-stranded DNA can be detected by dyes such as ethidium bromide and thiazole orange, but binding is unspecific, making these dyes useful solely as quantitative tools for DNA detection. Dervan and coworkers prepared 
8 1 1 Artificial (Pseudo)peptides for Molecular Recognition and Catalysis

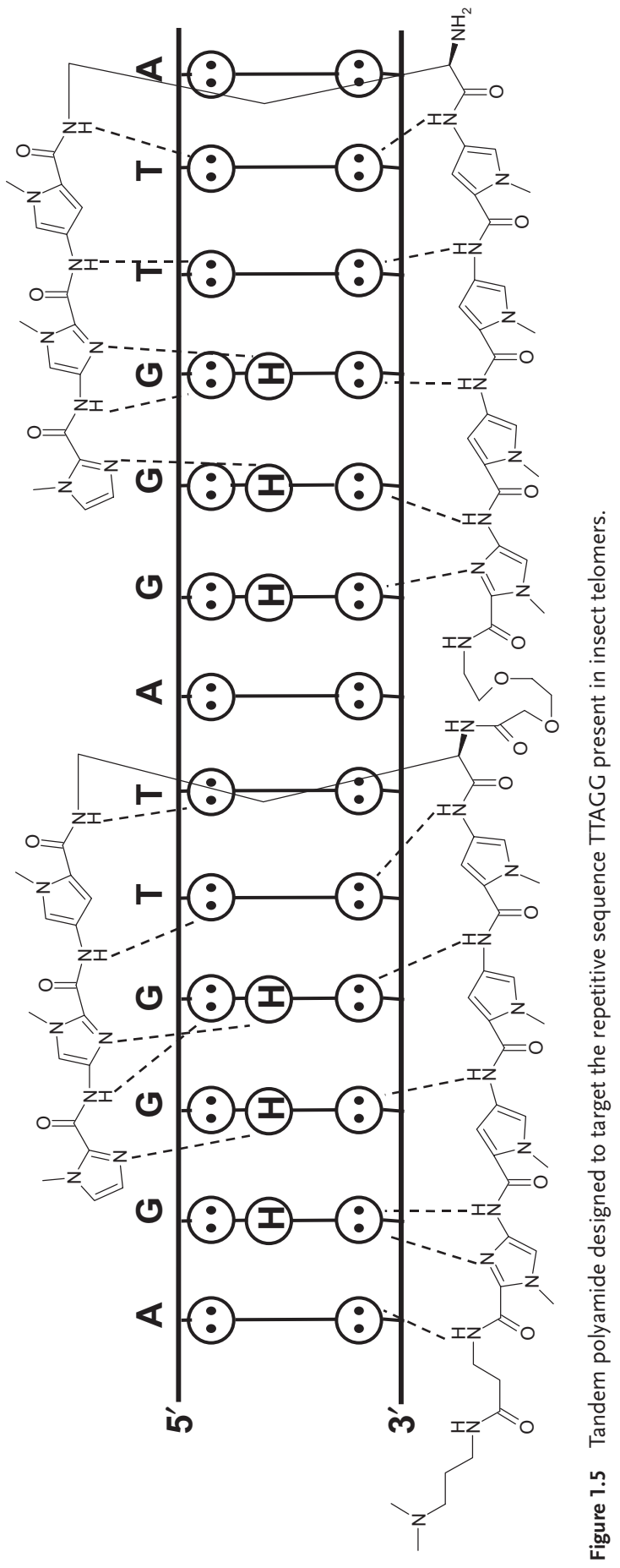


a series of eight-ring hairpin polyamides with tetramethyl rhodamine (TMR) attached to internal pyrrole rings and studied the fluorescence in the presence and absence of 17-mer duplex DNA [18]. In the absence of DNA, the fluorescence of the conjugates was strongly diminished compared with that of the free dye. This was hypothesized to result from the short linker separating the polyamide and the dye, which enables nonradiative decay of the excited state. The addition of increasing amounts of duplex DNA with a match sequence resulted in an increase in fluorescence until 1:1 DNA:conjugate stoichiometry was reached. Binding of the polyamide fragment to the minor groove of DNA results in forced spacing between polyamide and dye, thus diminishing any quenching effect.

In an impressive study by Laemmli and coworkers the ability of polyamide-dye conjugates to function in a genomic context was demonstrated [19]. A series of tandem polyamides was synthesized that interact specifically with two consecutive insect-type telomeric repeat sequences (TTAGG) (Fig. 1.5). The dissociation constant for the best polyamide was $0.5 \mathrm{nM}$, as determined by DNase I footprinting. Epifluorescence microscopy studies using Texas Red-conjugated analogs of these polyamides showed a very strong staining of both insect and vertebrate telomeres of chromosomes and nuclei. Convincingly, the telomere-specific polyamide signals of HeLa chromosomes colocalize with the immunofluorescence signals of the telomere-binding protein TRF1. Studies in live Sf9 cells seem to suggest rapid uptake of the conjugates, thus enlarging the potential of these compounds as human medicine. These results should be interpreted with caution, however, because the fluorescence studies were performed after fixation of the cells, which is known to dramatically increase the membrane permeability of cells [20].

In a related approach, Trask et al. targeted the TTCCA motif repeated in the heterochromatic regions of human chromosomes 9 , Y, and 1, using polyamides tagged with fluorescein [21]. Staining of the targeted regions was similar to that with the conventional technique (FISH), which employs hybridization of fluorescent complementary sequences. In sharp contrast, however, polyamide-dye conjugates do not require denaturation of the chromosomes.

\subsubsection{Gene Inhibition}

Gene expression requires recruitment of the transcription machinery to the promoter region, after which transcription of the coding region into mRNA can start. Inhibition of this process by polyamides can occur in either the promoter or coding region of a gene. The latter is more difficult to achieve, because any molecule noncovalently bound to the double helix will be expelled by RNA polymerases during the transcription of DNA. To address this issue polyamides have been tagged with alkylating agents such as chlorambucil and seco-CBI [22]. Indeed it was observed that alkylation occurs specifically at base pairs flanking the binding site of the polyamide. Whether this strategy enables effective inhibition of RNA polymerases has not yet been reported.

Most attention has been paid toward polyamides that act in the promoter region of a gene as competitors for the binding of transcription factors to DNA. Inhibition by polyamides can occur for a variety of reasons. A minor-groove-binding protein can be 
inhibited by a minor-groove polyamide because of steric hindrance. Binding of a protein with major-groove/minor-groove contacts can be similarly inhibited when the polyamide is crucially located in the minor groove. Alternatively, polyamides can also function as allosteric effectors that rigidify the shape of B-DNA, thus competing with a major-groove binding protein that requires helical distortion. Examples of protein-DNA complexes that have been inhibited by polyamides are TBP, LEF-1, Ets-1, and Zif268. In a key study, the viral HIV-1 gene was targeted (Fig. 1.6) [23]. The HIV1 enhancer/promoter region contains binding sites for multiple transcription factors, among them Ets-1, TBP, and LEF-1. Two different polyamides were designed to target DNA sequences immediately adjacent to the binding sites of these transcription factors. Cell-free assays showed that these ligands specifically inhibited binding of the transcription factors to DNA and consequently repressed HIV-1 transcription. In isolated human peripheral blood cells, incubation with a combination of these two polyamides resulted in $99 \%$ inhibition of viral replication, with no obvious decrease in cell viability. RNase protection assays indicated that the transcript levels of some other genes were not affected, suggesting that the polyamides indeed affect transcription directly.

However, despite the success in inhibiting binding of a large variety of proteins to DNA, problems remain with the class of major-groove-binding proteins that are not affected by the presence of ligands in the minor groove. Recent studies have been aimed at a generic solution that would inhibit binding of any sort of transcription factor [24]. Very promisingly, it was observed that attachment of an acridine intercalator to a polyamide locally extended and unwound the double helix and thus acted as an allosteric inhibitor for the major-groove binding of the GCN4 bZip protein.

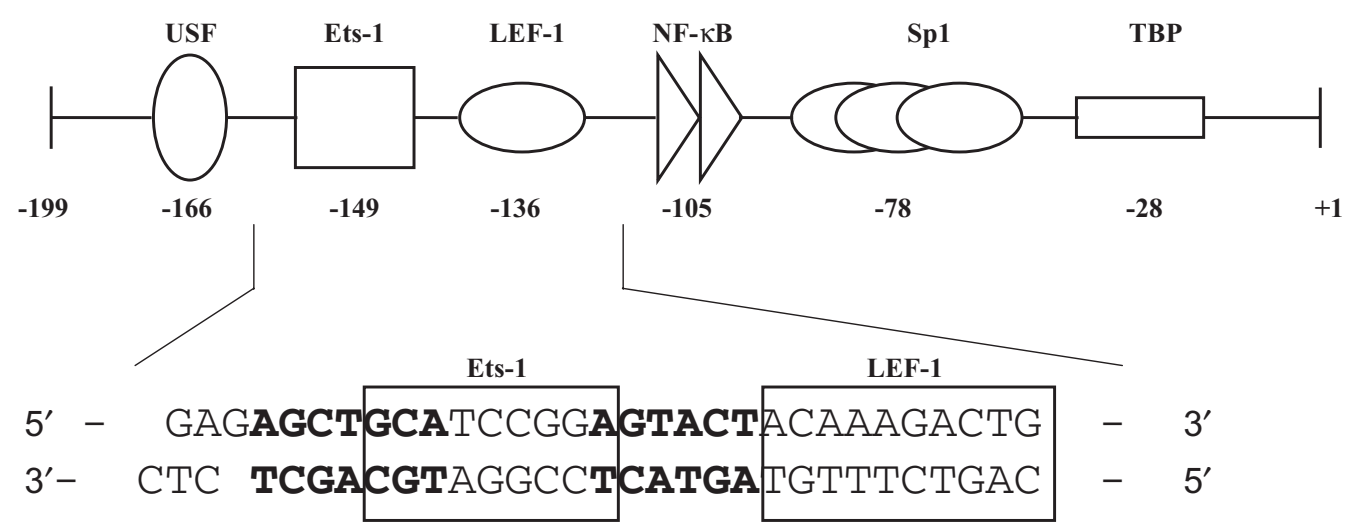

Figure 1.6 Schematic representation of the enhancer/promoter-region of the HIV-1 gene, with indications of the binding sites of the various transcription factors. In the enlargement, the binding sites of Ets-1 and LEF-1 are shown together with the binding sites of the polyamides (bold). 


\subsubsection{Gene Activation}

Gene activation can occur either by inhibiting the binding of a repressor protein or via recruitment of the transcription machinery. The first method is conceptually identical to the examples given in the previous section. For instance, polyamides have been successfully applied as an upregulator for transcription of the human cytomegalovirus MIEP [25]. The second method requires an entirely different role of the polyamide. Eukaryotic transcription factors are minimally composed of a DNAbinding and an activation domain. Most activator proteins also contain a dimerization element. Generally, gene transcription starts with binding of a transcription factor to the promoter-region, which induces recruitment of a series of other transcription factors to nearby promoter sites, and finally transcription is initiated. Dervan and coworkers showed that it is possible to replace an activator protein by an artificial minimum system composed only of short oligopeptides (Fig. 1.7) [26, 27]. In the mimic of the Gal4 yeast activator the DNA-binding domain was replaced with an eight-ring hairpin polyamide and the activation domain with VP2, a 16-amino-acid residue oligopeptide derived from the viral activator VP16. The two modules were linked with an eight-atom spacer giving a polyamide-peptide conjugate with a size not exceeding $3.2 \mathrm{kDa}$. Cell-free activation assays revealed an upregulation of almost 15 fold at concentrations that caused full occupancy of the binding sites. In a recent study, the influence of the linker on activation activity was investigated by examining a series of polyamide-peptide conjugates linked via rigid oligoproline sequences varying in size between 18 and $45 \AA$ [28]. Optimum activity was observed for a $\mathrm{Pro}_{12}$ linker, about $36 \AA$ in length.

The Hox proteins belong to a family of transcriptional regulators that bear the "home domain" - a trihelical DNA-binding domain that is conserved across vast evo-<smiles>COOCOC(=O)CCCC(=O)NCCCn1cc(NC(=O)c2cc(NC(=O)c3cc(NC(=O)c4cc(NC(=O)CCCNC(=O)c5cc(N(C)C(=O)c6cc(C(=O)NCCC(=O)NCCCN(C)C)n(C)c6)n(C)c5)cn4C)cn3C)cn2C)cc1N(C)C(=O)c1nccn1C</smiles>

Figure 1.7 A polyamide-based artificial transcription factor for Gal4. 
lutionary distances. Generally, Hox proteins by themselves bind DNA with low affinity and selectivity, but recently it has been suggested that heterodimer formation with the TALE class of homeoprotein causes high affinity and selectivity. Interaction between a Drosophila Hox (Ubx) and TALE (Exd) protein occurs via a short YPWM peptide. This conserved peptide is a feature of all Hox proteins. A polyamide was conjugated to this small oligopeptide to serve as a Hox-mimic [29]. Electrophoretic mobility shift assays revealed positive cooperative interactions between Exd and the conjugate in the formation of a ternary complex with DNA. It was, in fact, shown that the artificial activator was more effective than its naturally occurring equivalent, clearly illustrating the strong potential of this class of conjugates.

\subsubsection{Future Perspective}

The examples discussed in this section demonstrate the enormous achievements made in using polyamides, and their large potential as medicine for genetic diseases. However, some important hurdles still have to be passed to reach this ultimate goal. The main problem, as for many man-made synthetic structures, is the problem of delivery of the compounds to where they are needed - in the cellular nuclei in an organism. Evolution has decided, and for good reasons, that cells should not be a social room in which everybody can enter and leave as desired. Most polyamide studies have been performed on cell-free assays, clearly showing that the principles work. Also some encouraging results have been obtained in a cellular context, most notably inhibition of HIV-1 expression in human blood lymphocytes and also the induction of specific gain- and loss-of-function phenotypes in Drosophila embryos [30]. Recent studies, however, have revealed that polyamide uptake is largely cell-dependent and that in many cell lines polyamides are excluded from the nucleus [20,31]. The next research phase for these compounds will reveal whether a generic solution to the cellular uptake problem is feasible, or if each target will require different chemical modifications of the polyamides.

\section{2 .3}

\section{Peptide Nucleic Acids}

The second large class of (pseudo)peptides renowned for their ability to interact specifically with nucleic acids (both RNA and DNA) are the peptide nucleic acids (PNA). This research area also has been covered extensively in reviews [32-35] and we will therefore limit ourselves to illustrative and, where possible, recent examples.

\subsubsection{Chemistry and Interaction with DNA/RNA}

PNA is a DNA structural mimic in which the DNA backbone is replaced by a (pseudo)peptide, to which the nucleobases are connected by methylenecarbonyl linkages (Fig. 1.8) [36]. The structural simplicity and high accessibility of PNA has stimulated many scientists to study its properties in DNA/RNA recognition and to devise alternative structures [37, 38]. The strong binding properties of PNA to complementary ss DNA and RNA strands are best illustrated by the much higher melting points of the PNA-DNA and PNA-RNA dimers compared with the corresponding ds DNA and 


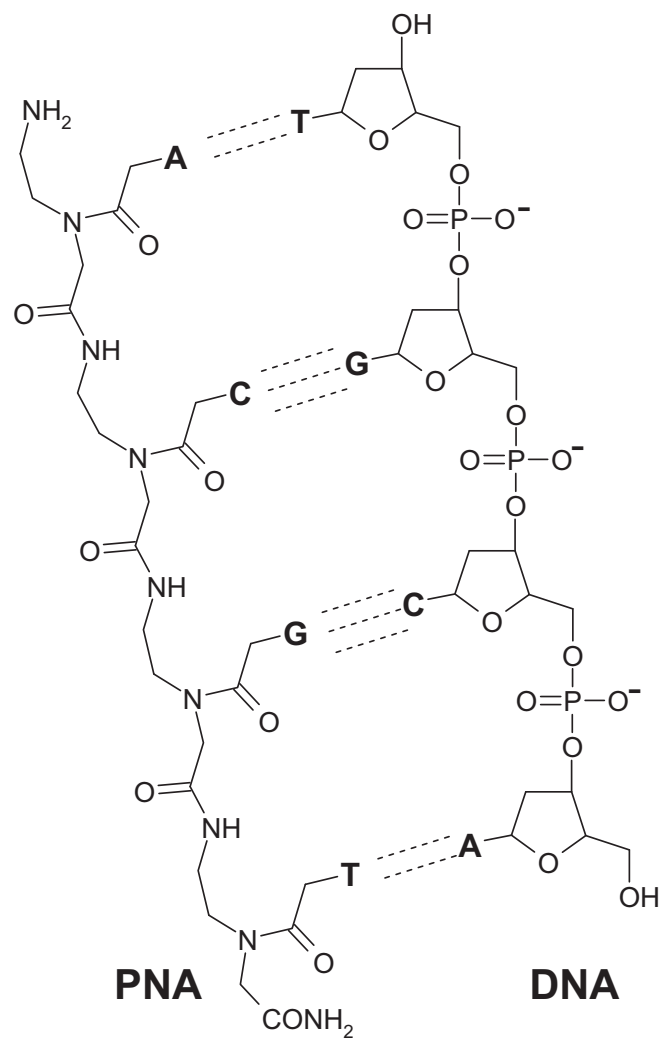

Figure 1.8. Chemical structures of PNA and DNA.

DNA-RNA duplexes (69.5 and 72.3 compared with 53.3 and $50.6{ }^{\circ} \mathrm{C}$, respectively) [39]. In addition, the PNA-DNA dimer proved much less tolerant of single base pair mismatches than the native DNA dimer. The increased stability of the PNA-containing dimers is primarily ascribed to the lack of repulsive electrostatic interactions between the two strands.

Originally designed in the early 1990s to serve as the third strand in triple helix DNA, the original N-(2-aminoethylglycine) PNA turned out to behave differently than expected. Addition of a 10mer homothymine PNA to complementary ds DNA resulted in helix invasion rather than triple-helix formation (Fig. 1.9) [36, 40]. In the resulting complex one PNA strand binds via Watson-Crick base-pairing antiparallel to the complementary DNA strands. A second PNA binds in a parallel fashion via Hoogsteen base-pairing. Triplex invasion is limited to homopurine tracks, similar to the behavior observed for triple-helix-forming oligonucleotides. Interestingly, the $\mathrm{PNA}_{2}$-DNA complexes are kinetically very stable with half-lives in the order of hours [41]. The stability is highly dependent on the ionic strength of the solution, however, with even physiologically relevant levels having a detrimental effect on binding. On the other hand, binding is greatly facilitated in cases where DNA is (tran- 


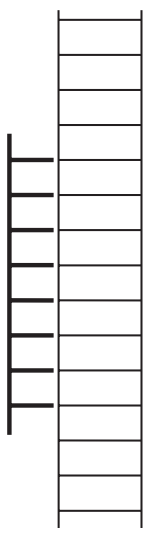

triplex formation

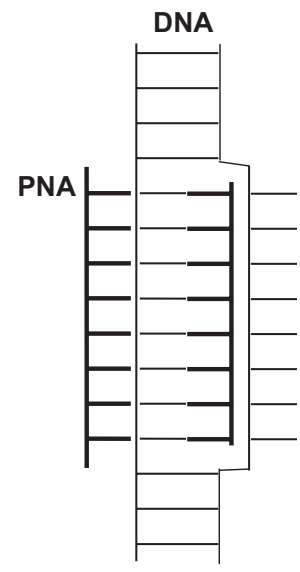

triplex invasion

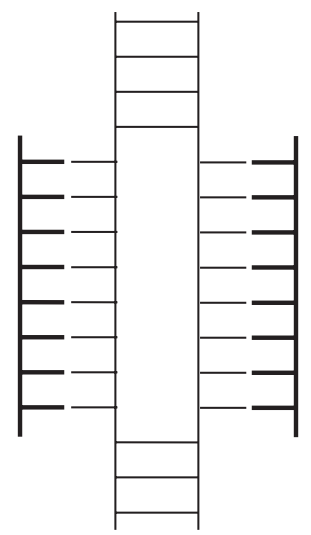

double duplex invasion

Figure 1.9 Different modes of PNA-interaction with dsDNA. PNA strands are depicted in bold.

siently) unwound, such as negative DNA supercoiling or by a passing RNA polymerase $[42,43]$. Other factors beneficial for complex stability are a covalent connection of the two PNA strands and replacement of the cytosines in the Hoogsteen strand for pseudoisocytosines, which do not require a low $\mathrm{pH}$ for protonation of the N3 position. Alternatively, it was recently shown that conjugation of a DNA-intercalator such as 9-aminoacridine to a PNA significantly increases binding affinity and enables helix invasion even at physiologically relevant ionic strength [44].

Also, sequences other than homopurine tracks can be targeted when pseudo-complementary PNA are used. Pseudo-complementarity means that the AT nucleobases in the PNA strands are replaced by a 2,6-diaminopurine/2-thiouracil pair [45]. This artificial base-pair is very unstable, because of steric hindrance. Ds DNA recognition in this case occurs via so-called double-duplex invasion, in which each PNA binds to the complementary DNA strand, thus relieving the steric repulsion present in the PNA duplex (Fig. 1.9).

Other attractive features of PNA that increase its potential as a therapeutic agent include a high chemical and enzymatic stability and low toxicity. A limiting factor, on the other hand, is the poor cellular (nuclear) delivery of this class of compounds [46]. These issues will be addressed in more detail in the selective examples discussed below.

\subsubsection{PNA as a Regulator of Gene Expression}

In-vitro studies showed that formation of the triple helix complex (PNA) ${ }_{2}-$ DNA can inhibit gene transcription by RNA polymerase [47]. Using an in-vitro replication runoff assay under physiological conditions, 14-mer PNA inhibited replication of mitochondrial DNA mutant templates by more than $80 \%$, whereas no inhibition of wildtype template replication was observed. From a medicinal perspective this is an important observation, because numerous genetic diseases result from single nu- 
cleotide polymorphism (SNP). Similarly, binding of either a 10-mer homothymidine PNA or a 15-mer PNA with mixed sequence to a plasmid (pBSA10) containing a complementary target sequence caused 90 to $100 \%$ site-specific termination of pol II transcription elongation [48].

Interestingly, transcription activation using PNA has also been achieved via two conceptually different approaches. Triplex invasion causes the expelled DNA strand to form a stable D-loop structure at the DNA-binding site, which is known to induce transcription. A series of C,T-PNA with different lengths (8mer - 20mer) was designed to bind to a 20 base-pair DNA homopurine sequence cloned into two promoter reporter vectors - pGL3-Basic, which carries a promoterless luciferase gene, and pEGFP-1, which carries a promoterless green fluorescent protein (GFP) gene [49]. In this setup, fluorescence readout is a direct reporter of the extent of transcription activation. Gel-mobility shift assays showed the strongest binding for the 16mer PNA, even at $1 \times 10^{-7} \mathrm{M}$ concentrations. Transcription activation was performed both in HeLa nuclear extracts and in human NF cells. Transfection of the cells in the in-vivo experiment was performed by preloading the plasmid with PNA and subsequent transfection using cationic liposomes. Both experiments resulted in high expression levels of the fluorescent protein, with an optimum for the 16- and 18-mer PNA.

The second approach toward gene activation is conceptually identical to the strategy employed with the minor-groove-binding polyamides already discussed [50]. A synthetic activator was formed by connecting a twenty residue Gal80-binding peptide sequence to a bis-PNA, i.e. two homopyrimidine PNA "clamped" via a poly(ethylene glycol) linker. The ability of this artificial activator to recruit Gal80 was assessed by binding of the PNA-DNA complex to Gal80 attached to agarose beads. Large amounts of the complex were retained for the DNA duplex containing five potential PNA binding sites. DNA retention was practically absent in a series of control experiments. The results of an in-vitro study on HeLa nuclear extracts were recently reported [51]. It was shown that promoter-targeted PNA alone acts as a strong inhibitor of basal transcription, for reasons already discussed, but that conjugation of the Gal80-binding peptide reactivates transcription.

Finally, in a very exciting and controversial study Richelson and coworkers have claimed that antigene and antisense PNA can pass the blood-brain barrier and can bind in-vivo to the neurotensin receptor (NTR1) in rats [52, 53]. Specifically, intraperitoneal injection of PNA inhibited the hypothermic and antinociceptive activities of neurotensin microinjected in the brain. Controversy has arisen because of the lack of evidence that the unmodified PNA used can indeed enter cells, not to mention nuclei. A second, more fundamental, problem lies in the design of the PNA used - all current information known about this class of compound suggests that it is unlikely that short hetero purine/pyrimidine PNA sequences can effectively bind to their complementary DNA strands.

\subsubsection{Antisense Properties of PNA}

Principally, oligodeoxynucleotides (ODN) and analogs can inhibit translation of mRNA in two ways. The first is activation of ribonuclease $\mathrm{H}$ (RNase $\mathrm{H}$ ) toward cleaving of the mRNA strand in the ODN-RNA complex. Although this property has been 
observed for several ODN analogs, for example phosphorothioates, PNA-RNA complexes do not seem to be substrates for RNase H. It has, however, been shown that antisense properties of PNA can arise from the second mode, in which either formation of the initial ribosomal translation machinery is inhibited or ribosome elongation in the coding region of mRNA is arrested. The efficiency depends on the type of complex formed [54]. Triplex-forming 10mer PNA were effective both when the AUG start codon was targeted, but also when bound to a downstream sequence in the coding region [55]. Duplex-forming PNA, however, seems effective in inhibiting formation of the translation machinery only; except in some special cases it is unable to stop translation once started. This difference is ascribed to the higher stability of the $(\mathrm{PNA})_{2} /$ RNA triplex and its tighter binding. Presumably, the "looser" binding of the duplex at the termini makes it easier for the elongating ribosome to expel it. Similar behavior has also been observed for minor-groove-binding polyamides. Also processes involving RNA, other than translation, have seemed to be sensitive to interactions with PNA. Examples include reverse transcription, telomerase activity, and RNA splicing.

Although most studies have been performed under cell-free in-vitro conditions, results in vivo have also been obtained. Most notably, Kole and coworkers reported on the antisense activity of PNA in a transgenic mouse containing the gene EGFP-654 encoding for the enhanced green fluorescent protein (EGFP) [56]. This gene was, however, interrupt by an aberrantly spliced mutated intron of the human $\beta$-globin gene. Consequently, in this model EGFP is only expressed in tissues in which an antisense oligomer (such as PNA) has restored the correct splicing. PNA was administered for one to four days via intraperitoneal injection, after which various organs were examined for the presence of EGFP. High activity was observed in the kidney, liver, and small intestine. Importantly, PNA activity was only observed for PNA that had four lysines connected to the C-terminus. A PNA containing only one lysine residue was completely inactive.

\subsubsection{Future Perspective}

Minor-groove binding polyamides and peptide nucleic acids are impressive examples of the progress made starting from a chemical design towards biologically active compounds. In-vitro studies have revealed the chemical robustness (and limitations) of these compounds as antigene and antisense agents, and it is striking that both classes are now more or less at the same stage of development, with the hurdle of cellular uptake preventing a wide applicability in vivo. In both instances, isolated examples have illustrated their potential in vivo, but a general solution has not yet been found. It should be remembered, however, that development of these classes of compound was started no more than approximately 15 years ago. The impressive progress made in this relatively short time and their wide use throughout the (bio)chemical community should evoke optimism for their future use as gene medicine. 
1.2.4

\section{Protein Recognition by (Pseudo)peptides}

DNA and RNA comprise a relatively small set of components and, in most cases, the three dimensional (sub)structure of the targeted site is well-known or can be easily deduced. Consequently, as we have seen in the previous section, highly specific artificial ligands that bind practically any desirable sequence with high affinity can be prepared by following a rather limited set of chemical rules. For proteins this is entirely different. The large number of amino acid residues, placed in a random order, forming a fascinating wealth of three dimensional structures with practically all biochemical functions possible, renders a rational approach to the design of artificial ligands an enormous challenge. Some emerging approaches will be discussed next. In accordance with the theme of this chapter, we will limit ourselves to a discussion of small (pseudo)peptides and, more specifically, their ability to recognize protein surfaces. This choice is motivated by the strong current interest in protein-protein interactions as part of the emerging functional proteomic era. Also, this avoids treatment of small molecular inhibitors of protein activity, which could easily fill a chapter on its own. The same is true for the sequence-selective recognition of short peptide fragments and isolated secondary structure elements, such as $\alpha$-helices and $\beta$-sheets, using artificial - not necessarily peptidic - compounds.

Many proteins are active only when part of a larger complex with other proteins. Small molecules that either inhibit or enhance protein assembly are important targets for pharmaceutical purposes, because they hold promise for the treatment of human diseases [57-59]. Complicating matters are not only the enormous structural diversity already mentioned, but also the large surface area involved in dimerization, which often exceeds $1100 \AA^{2}$. Importantly, however, it was found that the major contribution to the free energy of binding results from so-called "hot spots" on the protein surfaces about $600 \AA^{2}$ in size [60, 61]. Mutation of the amino acid residues that constitute these hot spots significantly reduce the binding affinity. The hot-spots are generally located in the center of the dimerization surface. Current views are that in this way a watertight seal can be generated around the energetically favorable interactions.

\subsubsection{Dimerization Inhibitors of HIV-1 Protease}

HIV-1 protease is a dimeric enzyme whose active site is composed of residues from both subunits [62]. Because the monomeric forms are completely inactive, agents which can inhibit dimerization are under intense investigation. In addition, whereas the HIV-1 virus continuously mutates and renders inhibitors ineffective, it seems that the dimerization domains are highly conserved. The dimerization interface of HIV-1 protease is a four-stranded, antiparallel $\beta$-sheet composed of the interdigitated $\mathrm{N}$ - and C-termini of the monomers. Chmielewski and coworkers prepared a dimerization inhibitor in which the peptide sequence derived from the $\mathrm{N}$-terminus was coupled, via a linker, to a peptide sequence derived from the C-terminus (Fig. 1.10) [63]. HIV-1 protease was inhibited with an $\mathrm{IC}_{50}$ of $350 \mathrm{~nm}$. In subsequent studies the influence of variations in both the peptide sequences and the linker were examined. Mutations in the peptide sequences led to a new inhibitor with a slightly 


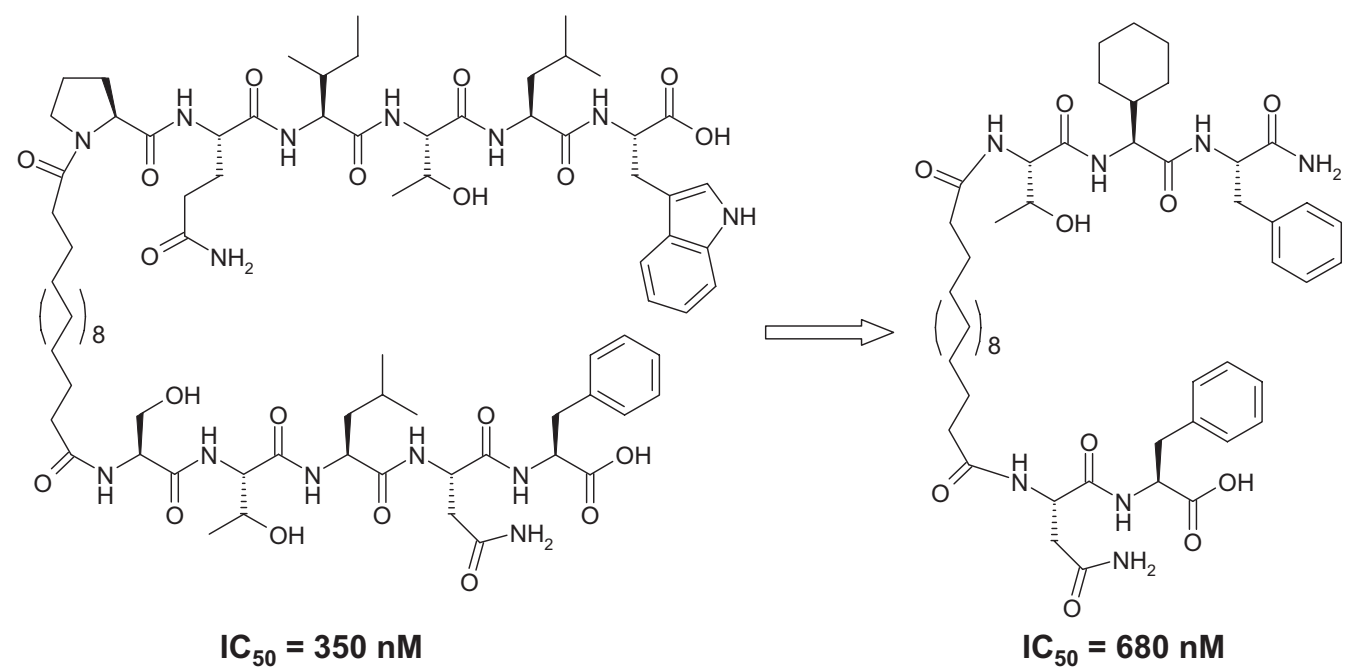

Figure 1.10 HIV-1 protease dimerization inhibitors.

higher $\mathrm{IC}_{50}$ of $680 \mathrm{~nm}$, but with a significantly lower molecular weight $\left(933 \mathrm{~g} \mathrm{~mol}^{-1}\right.$ compared with $1586 \mathrm{~g} \mathrm{~mol}^{-1}$ ) [64]. Interestingly, in this sequence a nonnatural amino acid with an appending cyclohexyl group was used. Linker studies revealed that rigidification of the spacer using naphthyl or dibenzofuran groups resulted in reduced activity of the inhibitor, even although models suggested that these linkers should position the two peptide sequences at the required $10-\AA \AA$ distance.

Intrigued by these studies, we reasoned that the reversible control of the distance between the two tethered peptides in this kind of inhibitor would lead to modulation of its activity. For this purpose we connected the two peptides initially employed by Chmielewski et al. to the Tren template via a rigid aromatic spacer [65]. Molecular modeling predicted that the distance between the two N-termini would be close to $10 \AA$ (presumably required for optimum activity) only in the presence of this spacer and when a $\mathrm{Zn}^{\mathrm{II}}$ metal ion was complexed by the Tren template. In the design of the system the third arm, necessary to impart rigidity to the $\mathrm{Zn}^{\mathrm{II}}$ complex but not used for enzyme recognition, was functionalized with a naphthalene unit to enable fluorescent readout for the protonation and/or $\mathrm{Zn}^{\mathrm{II}}$ complexation of the Tren template. We were able to verify our hypothesis using a fluorogenic substrate assay, which revealed enhancement of the inhibition of HIV-1 protease activity on the addition of $\mathrm{Zn}^{\mathrm{II}}$. Control experiments revealed that addition of EDTA (ethylenediaminetetraacetate) reversed this effect, because of depletion of the $\mathrm{Zn}^{\mathrm{II}}$ ion from the Tren template.

\subsubsection{Inhibitors of $\mathrm{p} 53 / \mathrm{Hdm} 2$ Interactions}

The p53 tumor suppressor is a multifunctional protein that regulates cell proliferation by induction of growth arrest or apoptosis in response to DNA damage and/or stress stimuli. The p53 protein is inactivated in most human tumors, which in more than $30 \%$ of soft tissue sarcomas can be linked to amplified expression of the gene 
coding for the oncoprotein human double minute 2 (hdm2). Hdm2 affects p53 in two ways: first, it inhibits $\mathrm{p} 53$ expression by binding to the transcriptional activation domain of the 553 gene and, second, a protein complex involving hdm 2 causes nuclear export of p53 and subsequent cytoplasmic degradation. Small molecules that inhibit formation of this complex might help restoring p53 levels in cancer cells. The X-ray crystal structure of the N-terminal domain of hdm2 bound to a 15-mer p53-derived peptide revealed a deep hydrophobic cleft to which the peptide binds as an amphipathic $\alpha$-helix [66]. On the basis of this knowledge a dodecapeptide was designed that inhibited hdm $2 / \mathrm{p} 53$ complex formation with an $\mathrm{IC}_{50}$ of around $8.7 \mu \mathrm{M}$, which served as a starting point for further optimization (Fig. 1.11) [67]. A jump forward was achieved when artificial amino acids were used. Among these were the $\alpha, \alpha$-disubstituted amino acids Aib ( $\alpha$-aminoisobutyric acid), which increased the propensity of the peptide sequence to adopt an helical structure and Pmp (phosphonomethylphenylalanine), which stabilized a salt bridge with an $\mathrm{Hdm} 2$ lysine residue. The resulting optimized eight-amino-acid pseudo-peptide had an $\mathrm{IC}_{50}$ value of $5 \mathrm{~nm}$ and in a cellular assay caused p53-dependent cell-cycle arrest in an Hdm2-overexpressing tumor cell line.

\begin{tabular}{|c|c|}
\hline peptide sequence & $\mathrm{IC}_{50}(\mathrm{nM})$ \\
\hline Ac-GIn-Glu-Thr-Phe-Ser-Asp-Leu-Trp-Lys-Leu-Leu-Pro-NH ${ }_{2}$ & $8673 \pm 164$ \\
\hline Ac-Phe-Met-Aib-Tyr-Trp-Glu-Ac ${ }_{3}$ c-Leu-NH ${ }_{2}$ & $8949 \pm 588$ \\
\hline Ac-Phe-Met-Aib-Pmp-Trp-Glu-Ac ${ }_{3}$ c-Leu-NH ${ }_{2}$ & $314 \pm 88$ \\
\hline Ac-Phe-Met-Aib-Pmp-FTrp-Glu-Ac ${ }_{3}$ c-Leu-NH ${ }_{2}$ & $14 \pm 1$ \\
\hline Ac-Phe-Met-Aib-Pmp-CITrp-Glu-Ac 3 C-Leu-NH ${ }_{2}$ & $5 \pm 1$ \\
\hline
\end{tabular}

Figure 1.11 The use of nonnatural amino acids to optimize an oligopeptide that inhibits the binding of human wild-type p53 to GSThdm2. Abbreviations for the nonnatural amino acids: Aib, $\alpha$-aminoisobutyric acid; Pmp, phosphonomethylphenylalanine; CITrp, 6chlorotryptophan; FTrp, 6-fluorotryptophan; $\mathrm{Ac}_{3} \mathrm{c}, 1$-aminocyclopropanecarboxylic acid.

\subsubsection{Artificial Antibody Mimics for Protein Recognition}

Inspired by the impressive achievement of the immune system to develop antibodies that bind nonendogenous protein surfaces with high selectivity and affinity, Hamilton and coworkers took up the challenge to develop an equivalent synthetic system. Structural diversity in antibodies arises from the presence of six hypervariable loops in the fragment antigen binding (FAB) region. Four of these loops generally take up a hairpin conformation and the remaining two form more extended loops. As a mimic, calix[4]arene was used as a rigid cyclic scaffold and the upper rim was functionalized with cyclic peptides containing an artificial 3-aminomethylbenzoyl amino acid to facilitate coupling to the platform (Fig. 1.12) [68]. Cytochrome $c$ was set as an initial target, because of its well-characterized structure and its positively charged sur- 


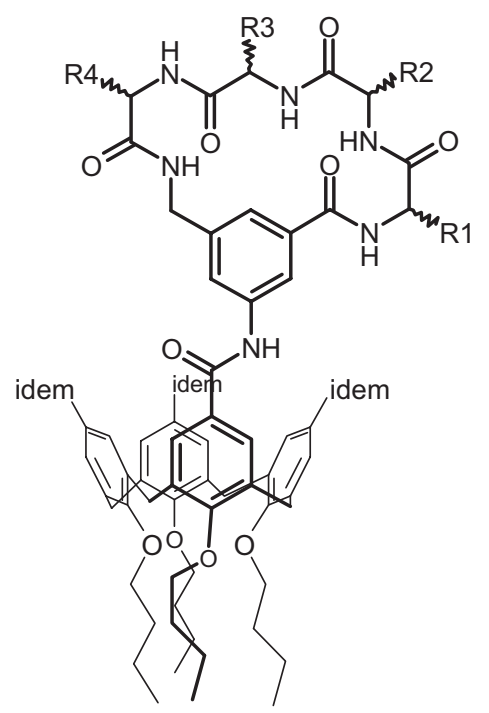

Figure 1.12 Design of an artificial receptor for chymotrypsin surface recognition.

face originating from the presence of several lysine and arginine residues. To introduce complementary charge in the antibody mimic the negatively charged sequence GlyAspGlyAsp was used in the loops. Protein binding was confirmed by gel-permeation chromatography, ${ }^{1} \mathrm{H}$ NMR spectroscopy, and kinetic assays on the ascorbate reduction of Fe $\mathrm{FII}^{\mathrm{II}}$-cyt $\mathrm{c}$. A follow-up study revealed that this compound effectively competes with cytochrome $c$ peroxidase, a natural high affinity partner of cytochrome $c$, forming a 1:1 complex with a binding affinity in the order of $10^{8} \mathrm{M}^{-1}$ [69]. It was recently shown that the same receptor also binds to the protein surface of chymotrypsin (ChT) and blocks the protein-protein interaction of ChT with a variety of proteinaceous inhibitors [70].

\section{3}

\section{Synthetic (Pseudo)peptide-based Supermolecules: From Structure to Function}

Although amino acid-based superstructures are almost the rule in the biological world, the number of synthetic supermolecules based on oligopeptides is relatively small. The main obstacles are the difficulty of predicting and controlling the conformation of amino acid sequences and, at the same time, introducing (un)natural functional groups in appropriate positions where they can perform recognition or catalytic tasks. Early examples in this field were extensively reviewed by Voyer a few years ago [71]. More recently, scientists have started to focus on the development of new foldamers [72] by introducing key structural elements in an artificial sequence that imposes conformational restriction on the oligopeptide. In this context, a foldamer is defined as an oligomer with a characteristic tendency to fold into a specific structure 
in solution, which is stabilized by noncovalent interactions between nonadjacent subunits. In recent years large progress has been made in the de-novo design of short peptide sequences ( $<100$ residues) that adopt a well-defined conformation. Several reviews have recently appeared that summarize the achievements in this field [73]. Recent accomplishments include metal-peptide models which, with remarkable success, control the placement of metals within designed secondary structures [74, 75].

\subsection{1}

\section{Catalytic (Pseudo)peptides}

One of the earliest examples of a short (14 amino acids), catalytically active sequence was reported by Benner et al. more than ten years ago [76]. The oligopeptide $\mathrm{H}_{2} \mathrm{~N}$-Leu-Ala-Lys-Leu-Leu-Lys-Ala-Leu-Ala-Lys-Leu-Leu-Lys-Lys-CONH ${ }_{2}$ is not highly organized at infinite dilution in aqueous buffer ( $\mathrm{pH} 7)$, having an $\alpha$-helix content of only $18 \%$. Increasing the concentration, however, induces aggregation into a four-helix bundle characterized by a much greater content of helix. The oligopeptide catalyzes the decarboxylation of oxaloacetate via an imine intermediate with three orders of magnitude rate acceleration relative to the uncatalyzed reaction. The catalytic activity is because of two factors. Placement of the reacting amine at the terminus of the helix causes a critical decrease of the $\mathrm{p} K_{\mathrm{a}}\left(\Delta \mathrm{p} K_{\mathrm{a}}=0.6\right)$. Second, the anionic transition state is stabilized by electrostatic interactions with the cationic lysine residues present on the peptide surface. As a consequence, imine formation is no longer the rate-determining step, which is at variance with the natural enzyme oxaloacetate decarboxylase.

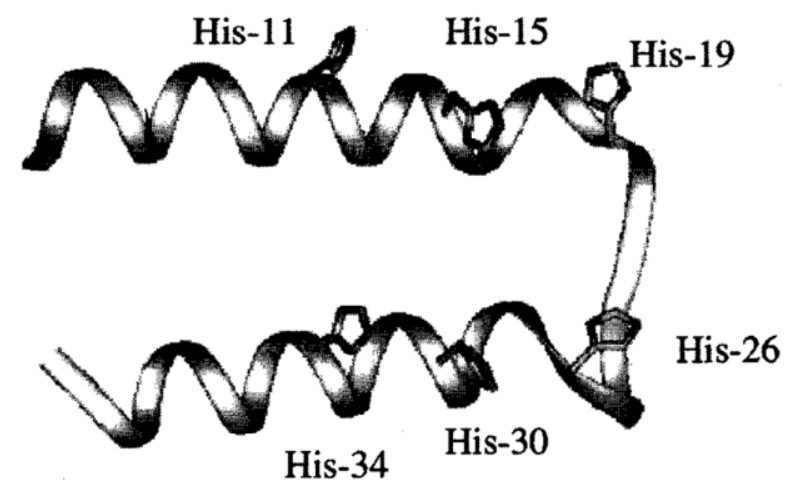

Figure 1.13 Baltzer's helix-loop-helix motif for the cleavage of carboxylate esters. 
Baltzer's group, exploiting the conformational preference of designed 42 amino acid sequences for a helix-loop-helix conformation [77], has systematically modified specific residues in key positions of the oligopeptide to catalyze the hydrolysis and transesterification reactions of p-nitrophenyl esters (Fig. 1.13) [78]. Imidazole-functionalized peptides obtained by introducing several histidines in the sequence were able to provide substrate recognition, and acceleration exceeding three orders of magnitude compared with $\mathrm{N}$-methylimidazole. For example, the sequence depicted in Fig. 1.13 hydrolyzes 2,4-dinitrophenyl acetate with a second-order rate constant of $0.18 \mathrm{M}^{-1} \mathrm{~s}^{-1}$ at $\mathrm{pH} 3.1$ compared with $9.9 \times 10^{-5} \mathrm{M}^{-1} \mathrm{~s}^{-1}$ for $\mathrm{N}$-methylimidazole.

Interestingly, it has been demonstrated that the reaction mechanism takes advantage of the cooperativity of two adjacent histidines, one acting as the nucleophile and the other as a general base. For flanking His-Lys sequences the unprotonated form of the histidine attacks the ester in the rate-determining step of the process followed by subsequent transacylation of the lysine. If several lysine residues are present, at low $\mathrm{pH}$, only those that flank the His are acylated. This leads to site-selective incorporation of an acyl residue in a natural sequence [79]. Direct alkylation of lysines occurs in sequences devoid of histidines. In this case the nucleophilicity of the lysines could be controlled by site-selective $\mathrm{p} K_{\mathrm{a}}$ depression [80]. As stated by the authors, the elucidation of the principles that control reactivity in such elementary processes is the first step toward the construction of biomimetic catalysts that accelerate reactions for which naturally occurring enzymes do not exist.

A pyridoxamine coenzyme amino acid chimera was introduced by Imperiali into designed $\beta \beta \alpha$ motif peptides (23-amino-acid sequences) to obtain a transamination catalyst (Fig. 1.14) [81]. The uncatalyzed transamination of $\alpha$-keto acids to $\alpha$-amino acids is a difficult reaction which is catalyzed efficiently by the coenzymes pyridoxamine phosphate and pyridoxal phosphate. A series of 18 peptides was synthesized

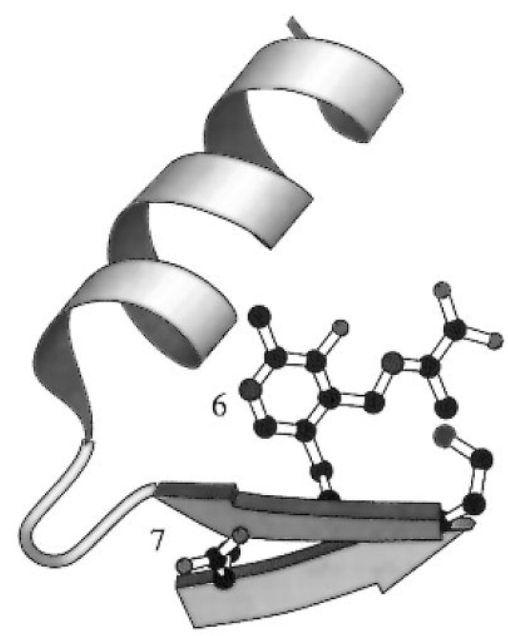

Figure 1.14 A pyridoxamine coenzyme amino acid chimera was introduced by Imperiali into designed $\beta \beta \alpha$ motif peptides (23-aminoacids sequences) to obtain a transamination catalyst. 
to create different microenvironments for the introduced pyridoxamine functionality. This led, in the best case, not only to acceleration of the transamination rate but also to promising enantioselectivity in the production of L-alanine (up to $27 \%$ ee).

Barton and her group [82] reported the activity of zinc-binding peptides tethered to rhodium intercalators. In these systems the intercalator provides DNA binding affinity and the metal-binding peptide contributes the reactivity. The strategy seems to be rather general because $\mathrm{Zn}^{\mathrm{II}}$-promoted DNA cleavage was observed for two widely different tethered metallopeptides. The structural features of one of the two are such that they place two imidazole units of histidines facing each other in a $\alpha$-helix conformation (Fig. 1.15). In this way they are directly involved in the binding of the metal ion. The other was modeled on the active site of the BamHI endonuclease. Specifically, a short $\beta$ hairpin was excised from BamHI restriction endonuclease and the sequence was such that it clustered three carboxylate groups (one from aspartic acid and two from glutamic acid) for metal-ion binding. The native protein is known to bind to DNA as a dimer and cleaves at 5'-GGATCC-3' palindromic sites to give four base 5' staggered ends. Barton has also studied other redox-active metals, for example copper, to induce oxidative cleavage. The results indicate that one of the critical issues in the design of an artificial nuclease is selection of the intercalator. Not all metallointercalators studied orient a metallopeptide for the initiation of DNA hydrolysis, and it might be necessary to vary linkers and ancillary ligands to optimize activity. The work done by Barton and others have also shown how extreme caution should be taken in evaluating the mechanism of action of a metallocatalyst when the metal ion can be involved in redox chemistry. Quite often what is assumed to be an hydrolytic mechanism eventually turns out to be oxidative. This can be observed for metals like copper, cobalt and, in selected cases, nickel also.

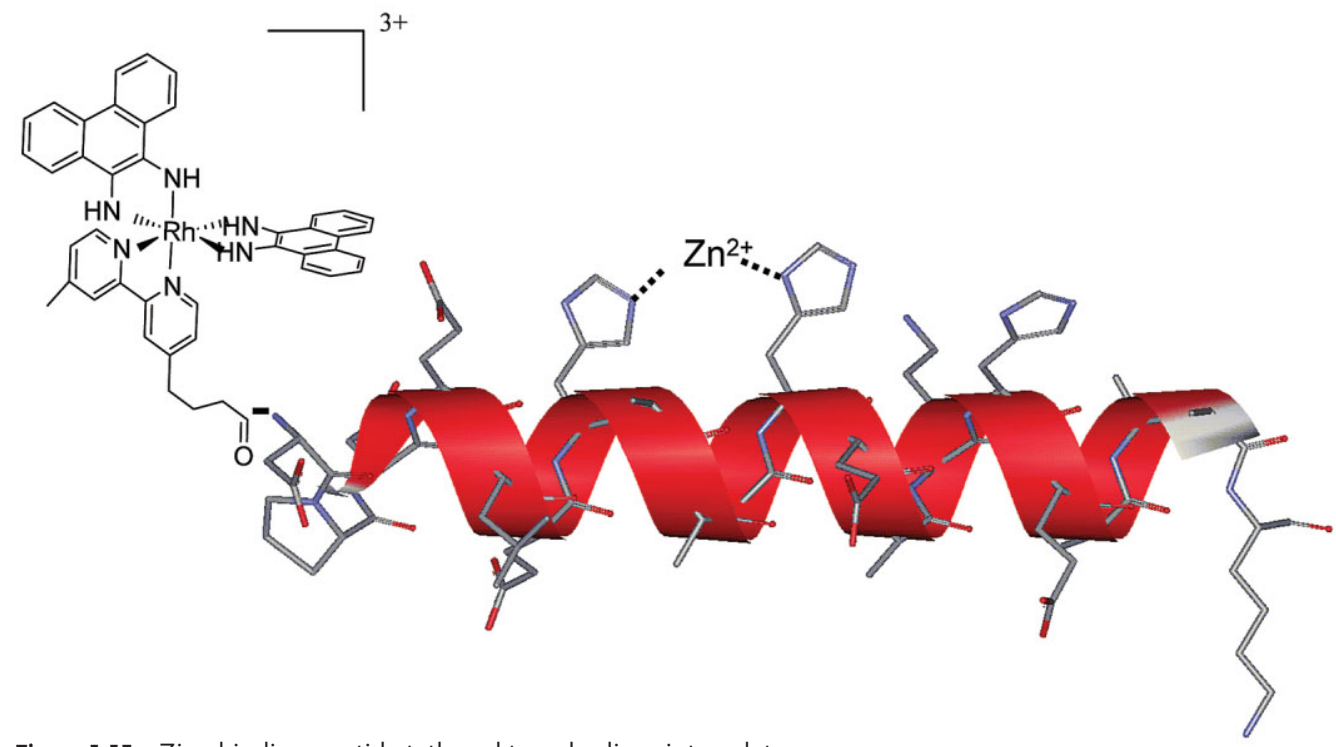

Figure 1.15 Zinc-binding peptide tethered to a rhodium intercalator reported by Barton. 
An interesting approach to the engineering of functional peptides is the introduction of synthetic unnatural amino acids in the sequence. The scope can be twofold synthetic amino acids can be used to limit the conformational freedom of the oligo or, alternatively, to introduce functional groups not available in the biological world [83]. Our contribution to this area has been the synthesis of the artificial amino acid ATANP [84] and its incorporation in a wide variety of oligopeptides. ATANP is characterized by the presence of an appended triazacyclononane which forms 1:1 complexes with metal ions such as $\mathrm{Cu}^{\mathrm{II}}$ and $\mathrm{Zn}^{\mathrm{II}}$ with strong affinities. Because these metals play an essential role in the hydrolysis of DNA and RNA, our aim has been to use this amino acid for the development of multinuclear transphosphorylation metallocatalysts. In collaboration with Baltzer's group 42-mer peptides analogous to that reported in Fig. 1.13 were synthesized, with the difference that these new sequences incorporated up to four copies of ATANP (Fig. 1.16) [85].

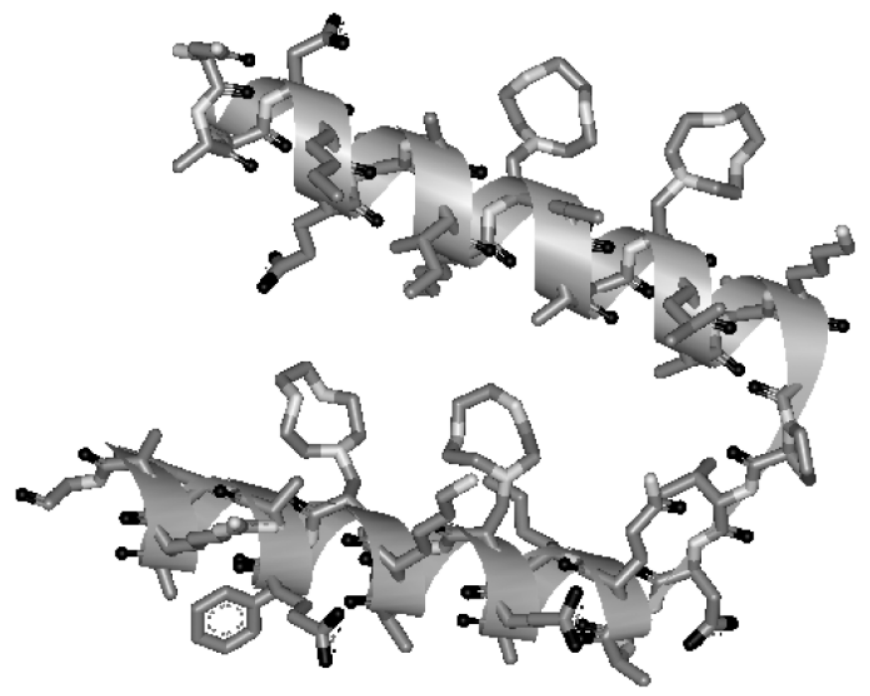

Figure 1.16 Artificial 42-mer sequence incorporating four copies of the unnatural amino acid ATANP used, as $\mathrm{Zn}^{\prime \prime}$ complex, in the cleavage of a RNA model substrate.

These new peptides also form helix-loop-helix motifs and bind $\mathrm{Zn}^{\mathrm{II}}$ ions with the triazacyclononane subunits present in the lateral arms of ATANP. It was observed that metal complexation causes a decrease in the helix content of the peptide. However, even on partial unfolding of the structure, acceleration of the cleavage of HPNP (2-hydroxypropyl-p-nitrophenyl phosphate, an RNA model substrate) was observed. Incorporation of ATANP in more structured peptide sequences controls the three-dimensional positioning of the metals even better and, consequently, significantly improves their catalytic activity. Thus the secondary structure of a $3_{10}$-helix can be used to position functional groups present in the amino acids at precise reciprocal dis- 
tance. In this conformation, when placed in positions $i$ and $i+3$, they will face each other with a separation of ca $6.2 \AA$, which is the pitch of the $3_{10}$-helix. An example is heptapeptide Ac-Aib-L-ATANP-(Aib) ${ }_{2}-\mathrm{L}-\mathrm{ATANP}-(\mathrm{Aib})_{2}-\mathrm{OMe}$, which was shown to fold into a 310 -helix in water. The two ATANP residues not only aid water solubility but can also form strong complexes with transition metals such as $\mathrm{Zn}^{\mathrm{II}}$ and $\mathrm{Cu}^{\mathrm{II}}[86]$. The dinuclear $\mathrm{Zn}^{\mathrm{II}}$ complex turned out to be a good catalyst for the cleavage of both an RNA model substrate (2-hydroxypropyl-p-nitrophenyl phosphate, HPNP) [87a] and plasmid DNA [87b]. In the latter, cooperative action between the metal centers was demonstrated by comparison of the activity of the mononuclear and dinuclear complexes. Tentatively, a mechanism is proposed which requires the formation of a supramolecular DNA-peptide complex, as shown in Fig. 1.17. The $k_{\psi}$ for the cleavage process $\left(\sim 1 \times 10^{-5} \mathrm{~s}^{-1}\right)$ enabled estimation of rate acceleration of approximately tenmillionfold over the uncatalyzed cleavage process.

The attachment of peptide sequences to conformationally flexible templates results in polypeptidic structures with the separate peptide chains adopting a random orientation relative to each other. Of special interest are those templates whose conformation can be rigidified by external stimulus, for example $\mathrm{pH}$ or the presence of a metal ion, because this can also induce organization of the peptide chains. One example of such a template is the tetraamine tris(2-aminoethyl)amine (Tren) whose three arms are aligned on complexation of a metal ion, for example $\mathrm{Zn}^{\mathrm{II}}$, in the tetradentate binding pocket. An artificial multinuclear metallonuclease subject to allosteric control by $\mathrm{Zn}^{\mathrm{II}}$ ions taking advantage of this property was recently described by us. A tripodal apopeptide was synthesized by connecting three copies of the heptapeptide $\mathrm{H}-\mathrm{Iva}$-Api-Iva-ATANP-Iva-Api-Iva- $\mathrm{NHCH}_{3}$ (where Iva is $(S$ )-isovaline and Api is 4-amino-4-carboxypiperidine) to the Tren template. The oligopeptides contain $\mathrm{C}^{\alpha}$-tetrasubstituted amino acids to induce helicity and ATANP to introduce a ligand for metal-binding. The apopeptide can bind up to four metal ions $\left(\mathrm{Cu}^{\mathrm{II}}\right.$ or $\left.\mathrm{Zn}^{\mathrm{II}}\right)$, one in the Tren subsite and three in the azacyclononane subunits [88]. The binding of metals to the Tren platform induces a change from an open to a closed conformation in which the three helical peptides are aligned in parallel, thus creating a pseudo-cavity with the azacyclonane units pointing inward (Fig. 1.18). In the transphosphorylation of phosphate esters, however, the behavior of this tripodal template was very peculiar. The tetrazinc complex catalyzed the cleavage of 2-hydroxypropyl-p-nitrophenyl phosphate (HPNP) whereas the free ligand was a catalyst for cleavage of an oligomeric RNA sequence with selectivity for pyrimidine bases. With HPNP, Zn ${ }^{I I}$ was acting as a positive allosteric effector by enhancing the catalytic efficiency of the system. With the polyanionic RNA substrate, $\mathrm{Zn}^{\mathrm{II}}$ was switching off the activity, thus behaving as a negative allosteric regulator. Our explanation of this different behavior is that the small cavity formed on metal-ligand coordination can accommodate HPNP but not the larger RNA oligomer. Consequently, the tetranuclear complex is a catalyst for cleavage of HPNP but not for cleavage of the oligonucleotide.

Although these examples concern the recognition and subsequent transformation of small substrates, Ghadiri [89] and Chmielewski [90] have described short peptides based on the coiled-coil folding motif $[91,92]$ that act as templates for the recognition of shorter sequences and, eventually, for their ligation. When the two short peptides 


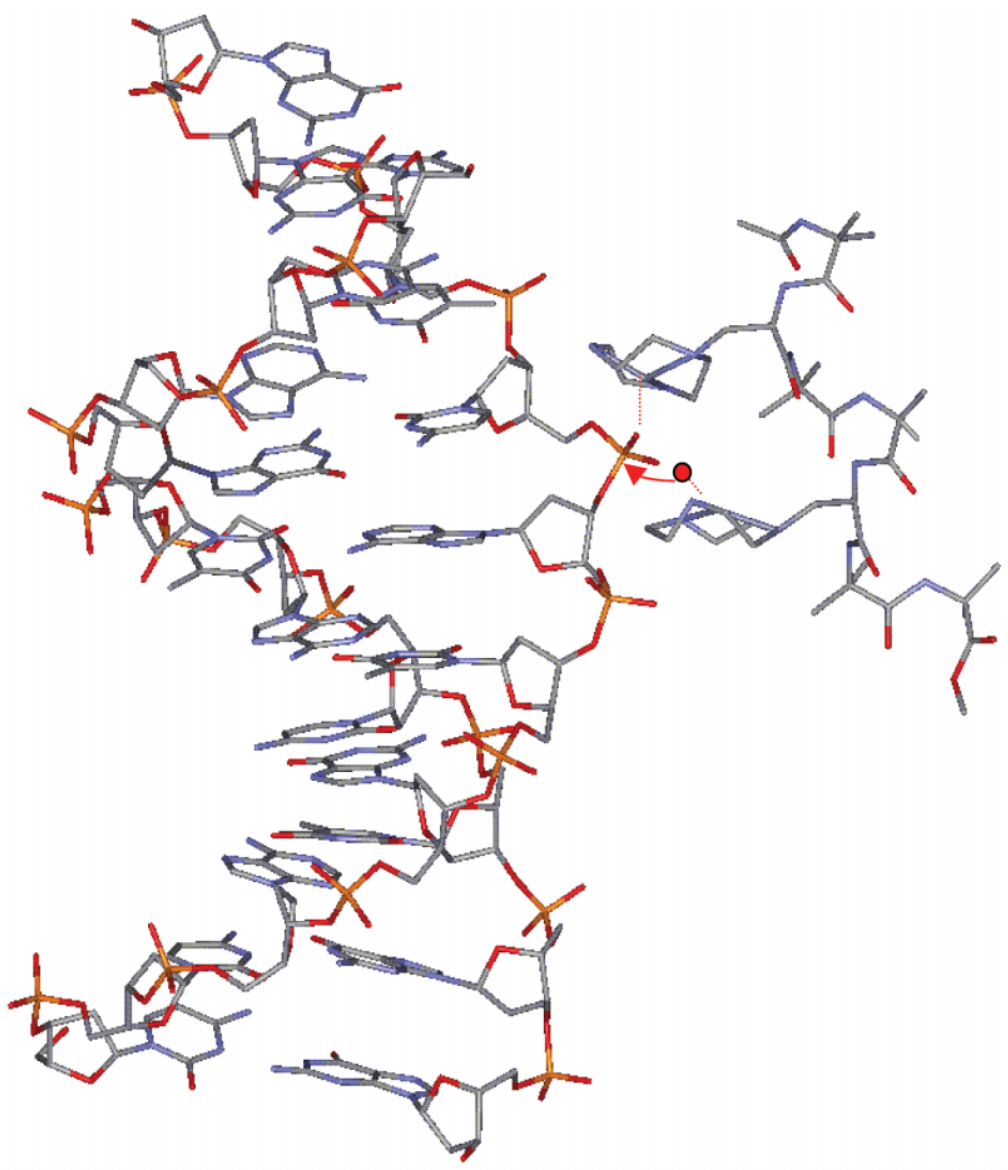

Figure 1.17 Peptide-DNA complex suggested as the active species in the hydrolytic process by Scrimin et al.

constitute each complementary pair of the templating unit, the systems are examples of self-replicating peptides [89c,d, 90]. For instance, a 33-residue polypeptide reported by Ghadiri [89] (Fig. 1.19) accelerates the ligation of a 16- and 17-amino-acid sequence using the coupling chemistry introduced by Kent et al. [93]. Initial rate accelerations were up to 4100 compared with a poorly matching system. In terms of catalytic efficiency this gives a value of $\left(k_{\text {cat }} / K_{\mathrm{m}}\right) / k_{\text {uncat }}$ of $7 \times 10^{5}$, larger than that found for catalytic antibodies [94]. The source of the catalytic acceleration is the specific recognition of the two substrates by the templating peptide which places the reactive termini in close proximity. The recognition selectivity was further exploited for chiroselective amplification of homochiral peptide fragments from a mixture of racemic substrates. The general limitation of the approach is that it is marred by product inhibition contrary to that found with the antibody-based catalyst [94]. However, by destabilizing the coiled-coil structure Chmielewski was able to enhance the catalytic 

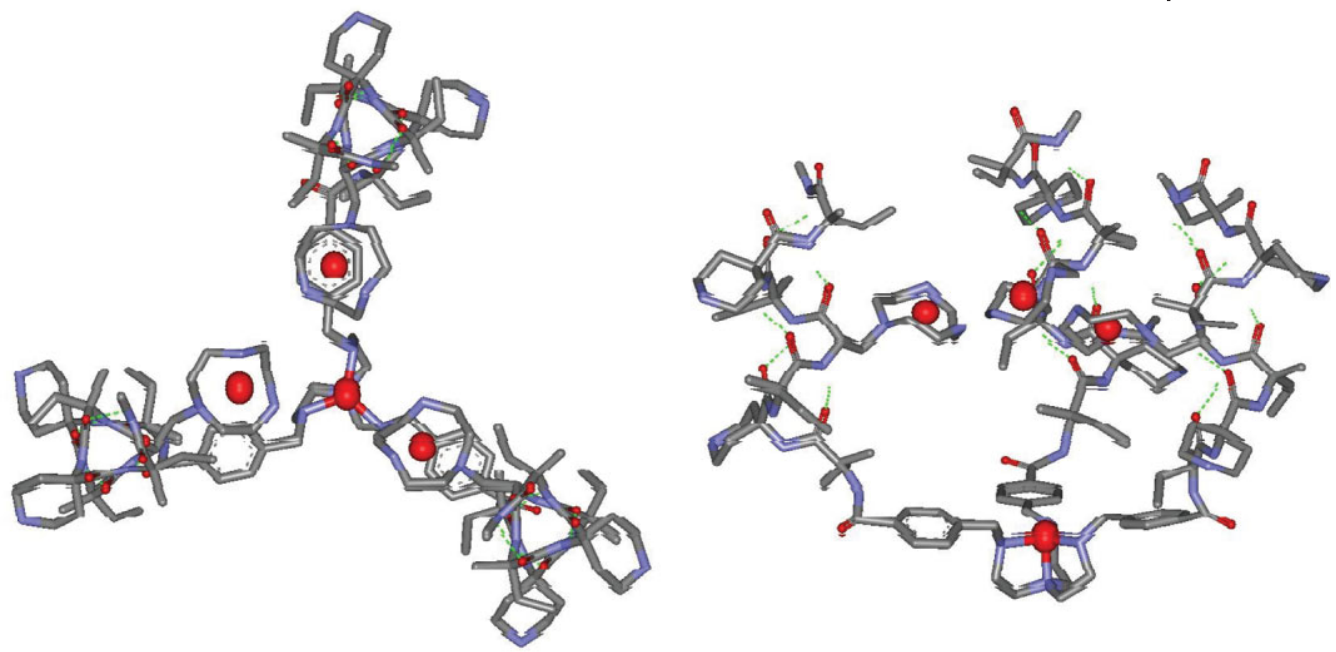

Figure 1.18 The binding of metals to the Tren platform induces a change from an open to a peptides are aligned in parallel, thus creating closed conformation in which the three helical a pseudo-cavity with the azacyclonane units pointing inward.

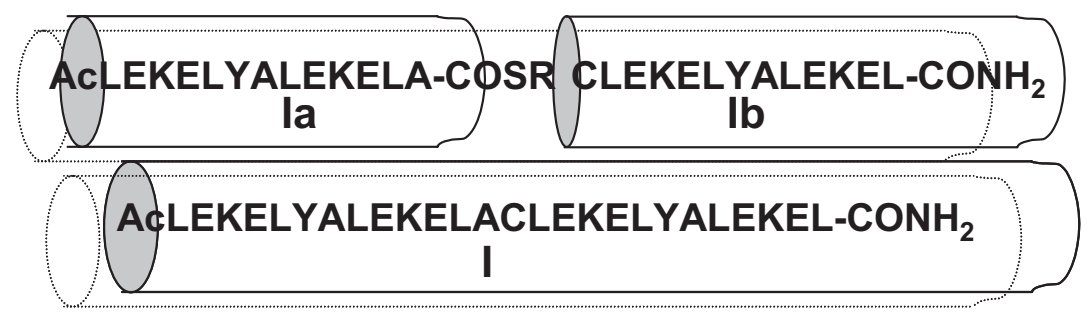

Figure 1.19 A 33-residue polypeptide reported by Ghadiri accelerates the ligation of a 16- and 17-amino acid sequence using the coupling chemistry introduced by Kent et al.

efficiency of the system [90b] and obtained a self-replicating peptide approaching exponential growth [95].

\subsection{2}

(Pseudo)peptides Altering Membrane Permeability

The amount of work performed on the synthesis of natural sequences able to alter membrane permeability is enormous [96] - a book would probably be needed to address this area properly. We will only provide examples of supramolecular peptidebased structures synthesized to perform this task. The cyclic peptides reported by Ghadiri et al. are excellent examples of conformationally restricted oligopeptides [97]. The peptides are composed of an even number of alternating $\mathrm{D}$ and $\mathrm{L}$ amino acids and are designed such that a flat conformation of the sequence is energetically favored. 


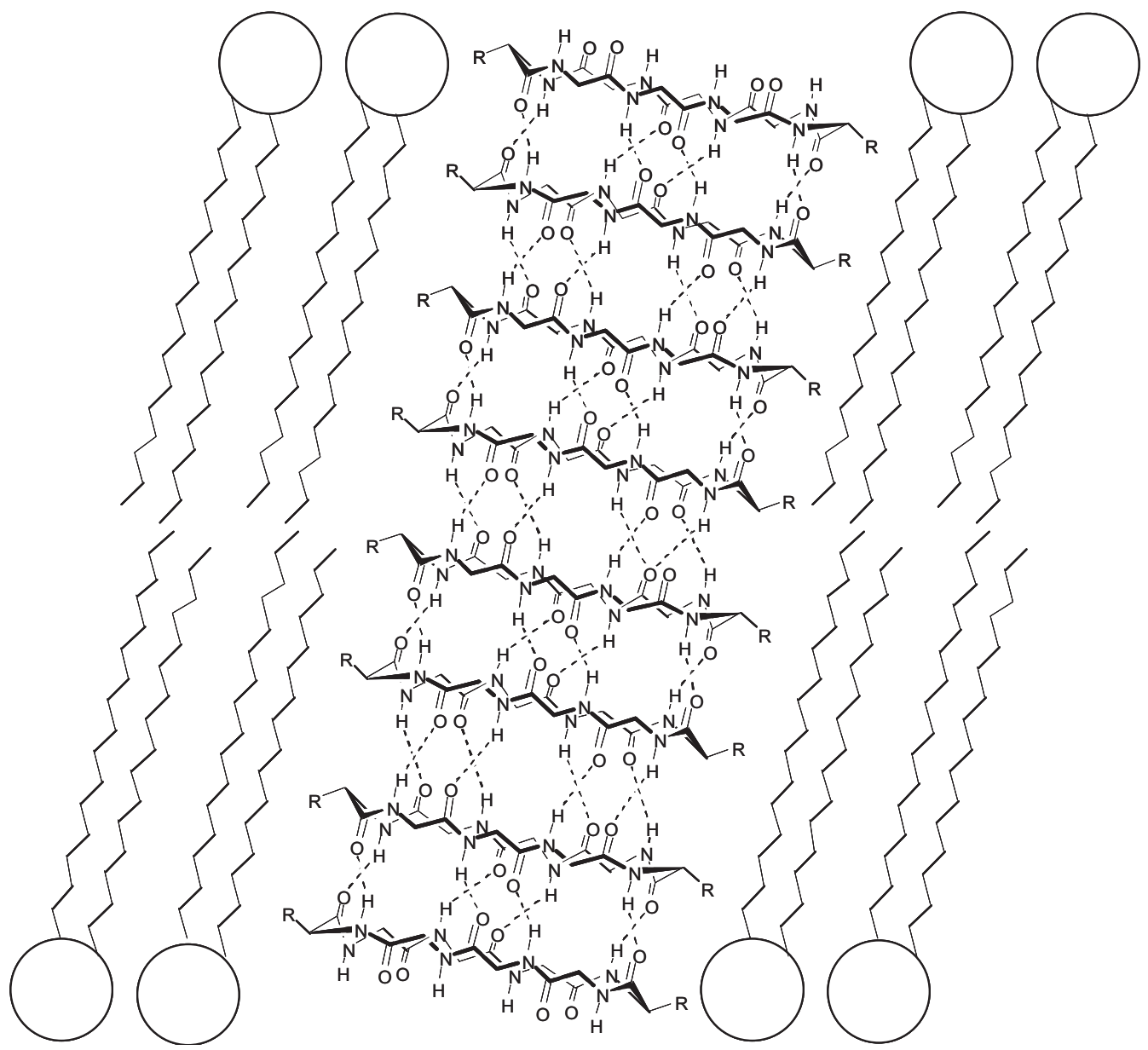

Figure 1.20 The cyclic peptides reported by Ghadiri et al. aggregate in the lipid membrane of bacteria and, by increasing its permeability, exert antibacterial activity.

In this conformation the amide functionalities of the backbone lie perpendicular to the plane of the ring structure, which consequently enables stacking of the cycles into $\beta$-sheet like tubular aggregates (Fig. 1.20). It was shown that the peptides aggregate in the lipid membrane of bacteria and, by increasing its permeability, exert antibacterial activity [98]. It was also demonstrated that they could mediate transmembrane transport of glutamic acid [99].

Crown ether-functionalized unnatural amino acids have been introduced in peptide sequences by Voyer and coworkers [100]. Incorporation of six crown-ether-functionalized amino acids in oligopeptides with a high propensity to form an $\alpha$-helix, resulted in the formation of artificial ion channels [100a,b,e,f]. A helical 14-residue peptide containing four polar but uncharged, benzo-21-crown-7 side-chains aligned 
along one face induced significantly more membrane leakage than analogous 21-mer or 7-mer peptides [100b]

Matile and coworkers [101] have developed synthetic $\beta$-barrels that bypass folding problems with preorganizing "non-peptide" staves but maintain the functional plasticity provided by $\beta$-strands. They have shown that rigid-rod $\beta$-barrels such as that depicted in Fig. 1.21 are indeed suitable for many tasks such as molecular recognition, transformation of organic molecules, and, relevant in this context, translocation. Their design is simple - short peptide strands are attached to each arene of a $p$-octaphenyl rod. Self-assembly or programmed assembly of complementary rods is driven by stave rigidity and formation of consecutive, interdigitating, intermolecular, antiparallel $\beta$-sheets between adjacent rods (i.e., minimized entropy losses and maximized enthalpy gains). The curvature needed to obtain barrels instead of precipitating amphiphilic tapes is initiated by arene-arene torsion angles $180^{\circ}$ in the p-octaphenyl scaffold and propagated by peripheral crowding with bulky $\mathrm{N}$ - and C-terminal amino acid residues. Suprastructural plasticity of $p$-octaphenyl $\beta$-barrels with "ideal" stability was demonstrated with regard to barrel truncation, elongation, contraction and expansion in water, and bilayer membranes.
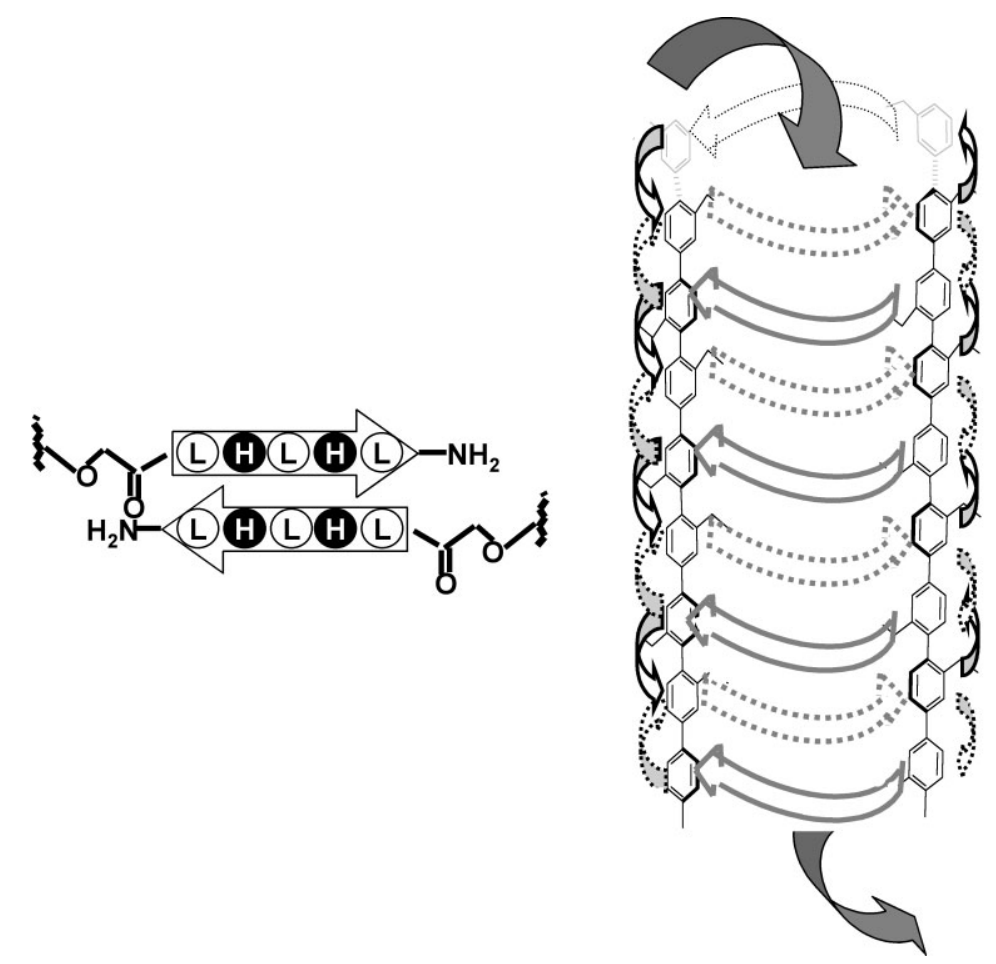

Figure 1.21 Synthetic $\beta$-barrels described by Matile obtained by formation of consecutive, interdigitating, intermolecular, antiparallel $\beta$ sheets between adjacent rods. 


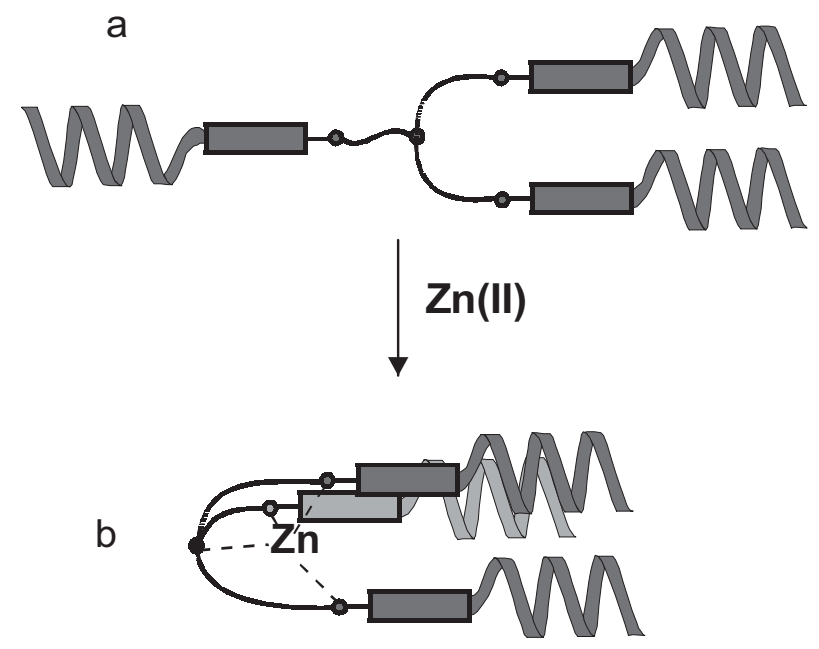

Figure 1.22 The change of conformation upon metal-ion complexation regulates the membrane activity of this tripodal polypeptide template.

We have conjugated peptide chains to the Tren template for synthesis of a system able to affect membrane permeability and subject to allosteric control. Thus three copies of peptide sequences from the peptaibol family, a class of natural antibiotic known to act on cell membranes by channel formation, were coupled to the Tren template. Experiments on leakage of trapped fluorescent dyes from unilamellar vesicles showed that a minimum of five amino acid residues per peptide chain was required for the formation of an active species. More important, it was observed that the tripodal apopeptide was far more effective than its $\mathrm{Zn}^{\mathrm{II}}$ complex. A mechanism was proposed in which the $\mathrm{Zn}{ }^{\mathrm{II}}$ ion causes a change in the conformation from extended to globular (Fig. 1.22). Molecular modeling indicated that in the extended form the apopeptide can span the lipid bilayer, thus enabling pore formation via clustering. In this example, binding of $\mathrm{Zn}^{\mathrm{II}}$ has an inhibitory effect on the activity of the peptide [102].

\section{3 .3}

Nanoparticle- and Dendrimer-based Functional (Pseudo)peptides

Nanosize clusters of several metals can act as templates for self-assembly of organic molecules. For example, organic thiols passivate the surface of gold nanoclusters forming a monolayer on their surface. This prevents growth of the particles and alters their solubility, depending on the functional groups present on the protecting monolayer. Synthetic procedures are available for the synthesis of these monolayer-protected gold nanoparticles (Au-MPC) both in apolar [103] and polar solvents [104]. These materials are characterized by the properties of the organic molecules that constitute the monolayer but also by the properties of the metal cluster core. Multivalency [105], which is at the basis of the amplification of the binding events with functional nanoparticles, has 
been exploited for the preparation of catalytic systems in which a cluster of functional groups led to catalytic activity which was not just the sum of the individual contributions [106]. We prepared a thiol-functionalized dipeptide by N-acylation of HisPhe speculating that, in this system, the free carboxylate/carboxylic acid of phenylalanine could constitute a simple function for catalysis providing, in conjunction with the imidazole of histidine, either base/nucleophilic and/or acid catalytic contributions. The nanoparticles were prepared by exchange reaction starting from polyether-functionalized watersoluble nanoparticles [104] thus affording the Au-MPC shown in Fig. 1.23 [107]. This new system could be studied in an aqueous solution in which hydrophobic interactions can be exploited for recognition of a substrate. Indeed these nanoparticles bind the lipophilic $p$-nitrophenyl ester of Z-protected L-leucine with a binding constant, $K_{\mathrm{b}}$, of $2 \times 10^{4} \mathrm{M}^{-1}$. Very interestingly, for the dipeptide-based catalyst there was no evidence of cooperativity between two imidazoles but, rather, the nucleophilic contribution of both

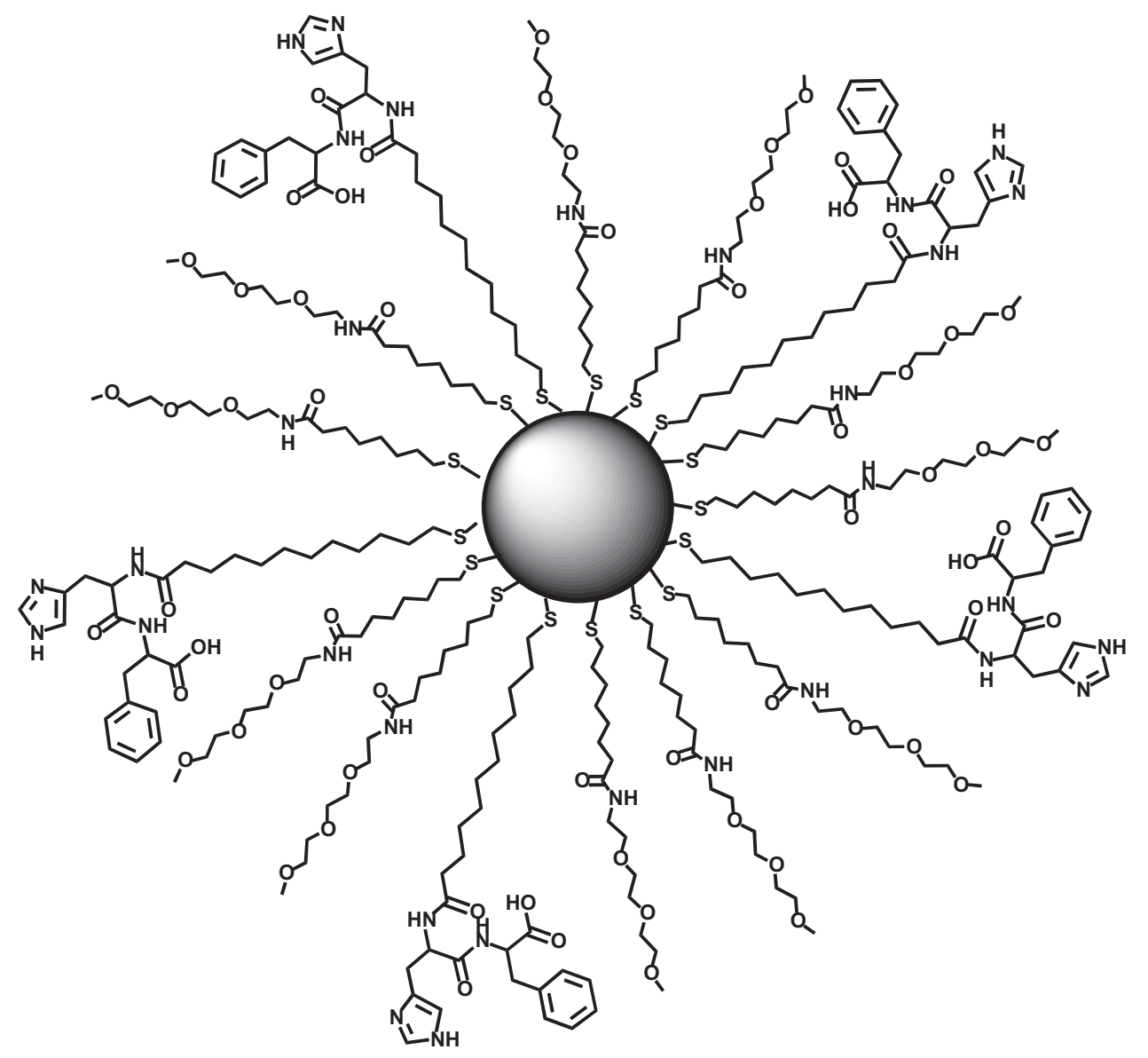

Figure 1.23 Dipeptide-functionalized gold nanoparticles for cleavage of carboxylate esters. 
an imidazole and a carboxylate in the cleavage of 2,4-dinitrophenylbutanoate (DNPB). The carboxylate contribution provided more than two orders of magnitude rate acceleration relative to the monomer. Consequently, these functional Au-MPC might be considered as models of an aspartic esterase and, as the real enzyme, have maximum efficiency below $\mathrm{pH} 5$.

The ultimate goal we had in mind was mimicry of an esterolytic enzyme not just by introducing minimal functional groups at the periphery of the nanoparticles but also by providing the appropriate environment (including chirality), as in the catalytic site of a protein. What we were pursuing was the self assembly of a synthetic protein by grafting short but conformationally constrained peptides on the surface of a gold nanopar-

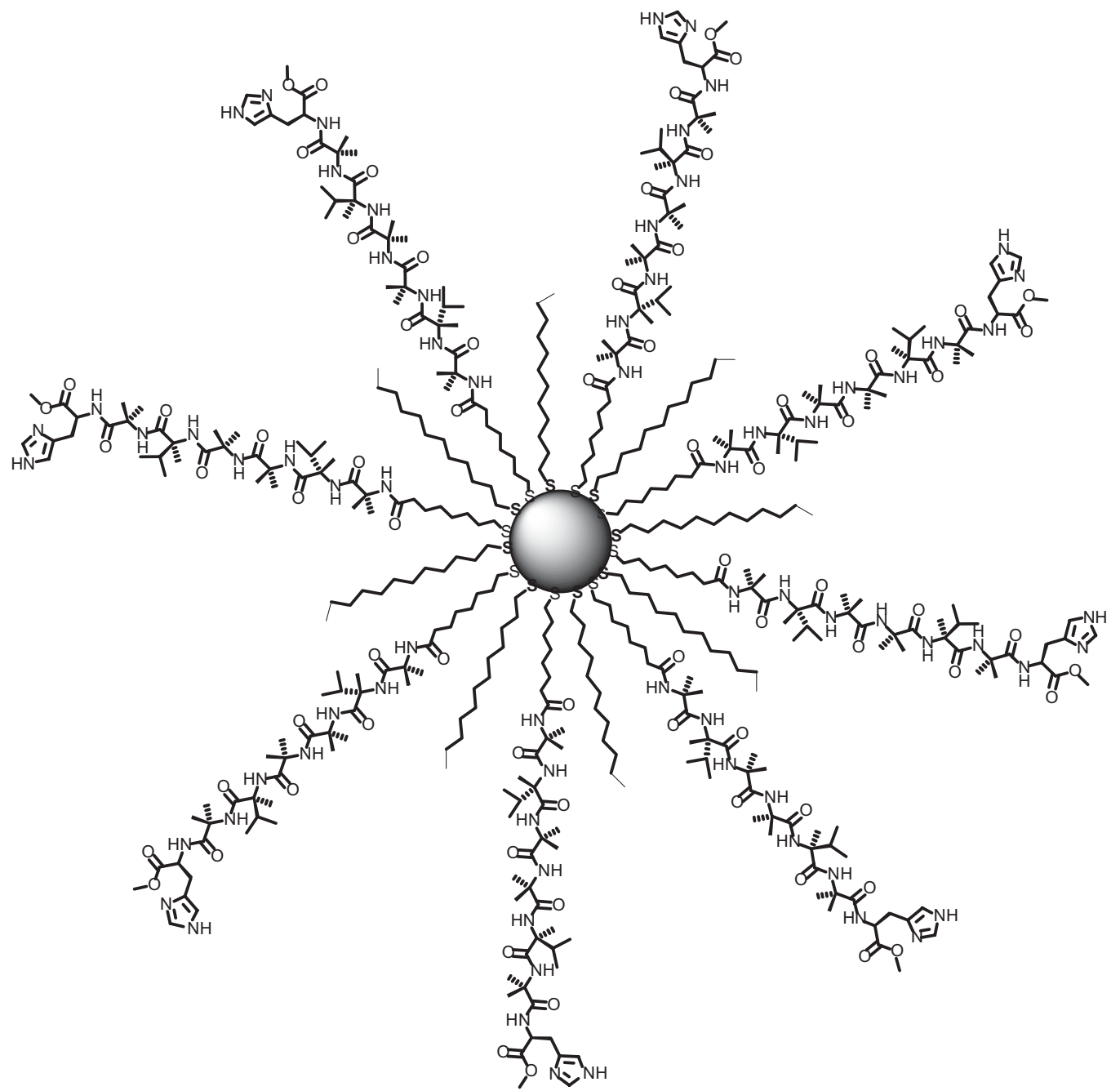

Figure 1.24 Nanoparticle covered with a monolayer comprising a $3_{10}$-helical heptapeptide. 
ticle. Very naively we made our first approach by using the rather lipophilic (although highly structured [108] in a helical conformation) peptide shown in Fig. 1.24 [109] assuming that the imidazole would be sufficient to ensure solubility in water. Although the exchange reaction with unfunctional MPC was successful, the resulting system proved poorly soluble not only in a aqueous solution but also in a variety of solvents of different polarity. The probable explanation we proposed was that the packing of the peptide in the monolayer was too tight, resulting in an extended network of intramonolayer hydrogen bonds preventing solution. With these studies we learned two lessons - first, that water-soluble nanoparticles had to be used for the exchange reaction and, second, that exchange of the thiols had to be limited to avoid overcrowding in the monolayer. By applying these rules of thumb we succeeded in preparing nanoparticles covered by a monolayer comprising the dodecapeptide shown in Fig. 1.25. The se-

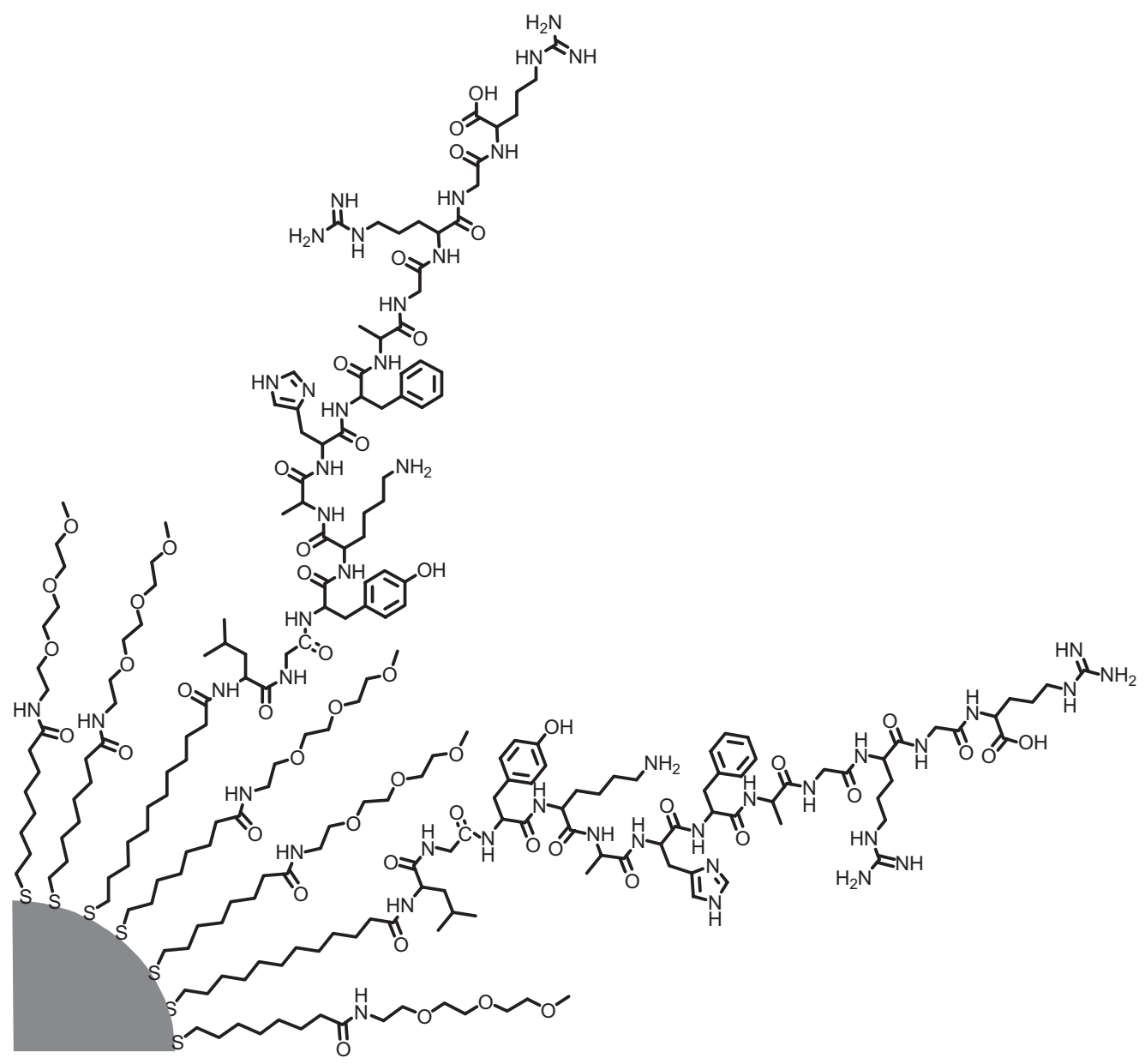

Figure 1.25 The functional groups present in this peptide sequence covering a gold nanocluster catalyze the hydrolytic cleavage of a carboxylate ester. 
quence terminates with the free carboxylate of arginine and has several functional groups potentially active for catalysis of the cleavage of a carboxylate ester - one histidine, flanked by hydrophobic amino acids, one lysine, and one tyrosine. These nanoparticles were fully soluble in water in a wide $\mathrm{pH}$ range and had remarkable activity in the cleavage of DNPB. However, whereas the dipeptide-functionalized Au-MPC were particularly efficient at low $\mathrm{pH}$, these new nanoparticles proved particularly effective at $\mathrm{pH}>8$, a clear indication that they were working preferentially with a basecatalyzed or nucleophilic mechanism involving high- $K_{\mathrm{a}}$ species. Complete analysis of the system is still in progress but we know already that the rate acceleration at pH 10 is ca. two order of magnitude larger than that determined with the dipeptide-functionalized nanoparticles whereas at low $\mathrm{pH}$ the acceleration is not so different.

Peptide dendrimers were prepared by solid-phase peptide synthesis [110]. Monomeric dendrimers were first obtained by assembly of a hexapeptide sequence containing alternate standard $\alpha$-amino acids with diamino acids as branching units. The monomeric dendrimers were then dimerized by disulfide-bridge formation at the core cysteine. Peptide dendrimers composed of the catalytic triad amino acids histidine, aspartate, and serine catalyzed the hydrolysis of $N$-methylquinolinium salts when the histidine residues were placed at the outermost position. The dendrimer-catalyzed hydrolysis of 7-isobutyryl- $N$-methylquinolinium followed saturation kinetics with a rate acceleration $\left(k_{\text {cat }} / k_{\text {uncat }}\right)$ of 3350 and a second order rate constant $\left(k_{\text {cat }} / K_{\mathrm{M}}\right)$ 350-fold larger than that of the 4-methylimidazole-catalyzed reaction; this corresponds to a 40-fold rate enhancement per histidine side chain. Catalysis was attributed to the presence of histidine residues at the surface of the dendrimers.

Ghosh et al. [111] demonstrated for the first time that discrete molecules comprising leucine zippers tethered to a core dendrimer provide the necessary molecular framework for constructing both monodisperse and fibrillar supramolecular assemblies that span the nanometer to micrometer range. The ability to integrate protein/protein self-assembly principles with dendrimer architecture enabled the facile self-assembly of hybrid dendrimer-protein complexes potentially useful for protein, DNA, or RNA recognition. These novel leucine-zipper dendrimers might provide a rich platform for constructing and utilizing a new class of programmable biomaterial with helical secondary structure. Ghosh's group design entailed choosing a dendrimer scaffold that did not sterically occlude peptide assembly and a series of peptides capable of noncovalent assembly. For the dendrimer, they used the zero generation PAMAM [112] core-functionalized with maleimides, thus enabling chemoselective covalent tethering to cysteine-containing peptides. The peptides consisted of the $\mathrm{pH}$-sensitive leucine zippers with hydrophobic cores and polar exteriors that can form tetramers, which were further modified with a Cys linker at the Cterminus. 


\section{4}

\section{Combinatorial Selection of Functional (Pseudo)peptides}

One of the important advantages of a peptide sequence over other building blocks is that solid-phase synthesis and, hence, a combinatorial approach to the preparation of libraries [113] of molecules can be accomplished with ease. The challenge in these cases is to devise methods for screening of these libraries. This means the possibility of estimating the binding strength for a specific target and, depending on the final use of the systems, evaluation also of their activity as catalysts or sensing devices. In contrast with the examples described above, which have in common the rational design of the functional (pseudo)peptide, the combinatorial approach is, by definition, an (almost) totally random selection approach. For example, Miller et al. [114c,d] have described the combinatorial synthesis of a 39-member library of five-amino-acid peptides. Screening of the catalytic activity for converting myo-inositol into D-myo-inositol-1-phosphate revealed one of the members to be an extremely efficient kinase mimic (Fig. 1.26). Delivery of a phosphoryl group to one of the three hydroxyl sites of the substrate exclusively was observed with ee $>98 \%$. Further focusing of the library led to even more remarkable results. Although previous work by the same group using conformationally restrained short sequences in asymmetric transacylation reactions [115] led to promising results with high enantioselectivity factors $(>50)$ this peptide does not seem to be at all organized. Clearly more research is needed to understand the formation and structure of the catalyst-substrate complexes and propose a rationale for these exciting results.

Functional metal peptides are appealing targets. Novel peptide-based catalysts for alkene epoxidation from metal-binding combinatorial libraries were obtained by Francis and Jacobsen [116] A combinatorial approach to hydrolytic metallopeptides for cleavage of phosphates was reported by Berkessel and Herault [117] who prepared a 625-member library of undecapeptides. Their strategy enabled direct on-beads screening of the library with a chromogenic model phosphate. In this way they were able to find active hits whose efficiency was also tested in homogeneous solution. Combinatorial optimization of the tripeptide $\mathrm{Xaa}-\mathrm{Xaa}-\mathrm{His}$ for complexation to $\mathrm{Ni}^{\mathrm{II}}$

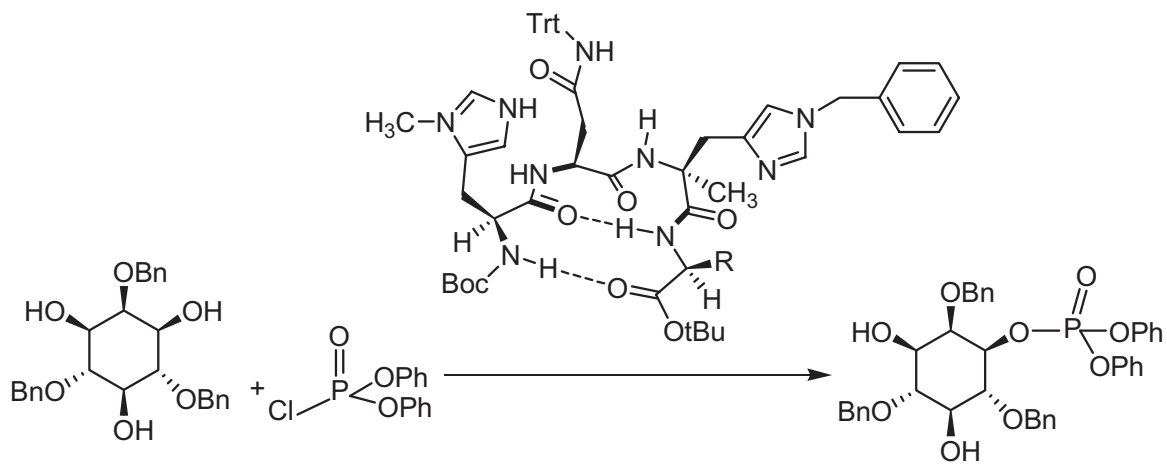

Figure 1.26 Miller's peptide catalyzes the conversion of myo-inositol into D-myo-inositol-1-phosphate. 
and deoxyribose-based (oxidative) cleavage of B-form DNA was also performed by Long and his coworkers [118]. The procedure they employed was to generate two libraries (by using 18 naturally occurring amino acids and excluding Cys and Trp) in which the first and second positions of the ligand were varied. The optimized metallopeptide $\mathrm{Ni}^{\mathrm{II}}$-Pro-Lys-His was found to cleave DNA an order of magnitude better than $\mathrm{Ni}^{2+}-\mathrm{Gly}-\mathrm{Gly}-\mathrm{His}$, the reference compound used as a starting point for the selection process. Interestingly, metal complexation and the T/A-rich site selectivity of the optimized metallopeptide were not altered and DNA binding affinity was only slightly increased. Thus the increased activity observed is mostly related to the geometry of binding, as is suggested by molecular models.

The stereoselective catalysis of a series of rather different reactions was performed by Hoveyda's group using metallopeptide complexes. In this work the highly crucial identification of the most effective chiral ligand/metal salt couple for a specific process was performed via preliminary parallel screening of different metal precursors employing readily modifiable (modular) ligands. In all instances peptide-based Schiff bases with different $\mathrm{O}, \mathrm{N}$ or $\mathrm{P}$ donors were used in the presence of both early and late transition metal ions. The development of efficient and highly stereoselective $\mathrm{C}-\mathrm{C}$ bond-forming processes such as $\mathrm{Ti}^{\mathrm{IV}}$-catalyzed addition of $\mathrm{CN}$ to epoxides [119] and imines [120], $\mathrm{Al}^{\mathrm{III}}$-catalyzed addition of $\mathrm{CN}$ to ketones [121], $\mathrm{Zr}^{\mathrm{IV}}$-catalyzed dialkyl addition of zinc to imines [122], and $\mathrm{Cu}$-catalyzed conjugate addition to enones [123] and allylic substitution [124] have been achieved. As an example, pyridinyl peptidic derivatives have been found to be effective chiral ligands for the Cu-catalyzed allylic substitution of di- and trisubstituted alkenes. The newly catalytic system enabled the synthesis of $(R)-(-)$-sporochnol with $82 \%$ ee and $82 \%$ overall yield [124]. The strategy for selection of the optimum reaction conditions was based on a series of repeated steps. Similar enantiomeric excesses were obtained by using a nonrational approach based on screening of parallel libraries of substrates, solvents, and metal ions [120a, 122]. This might indicate that small, focused libraries might provide results as good as a rational but more time-consuming approach in the selection of a catalytic system.

An important aspect was raised by Gilbertson in selecting catalysts from peptidebased phosphine ligands for late transition metal ions $[125,126]$ - that of the tuning of the best chiral ligand/substrate couple. This point emphasizes the quest for catalysts which are rather specific for a substrate, a property typical of enzymes. By studying the $\mathrm{Pd}^{\mathrm{II}}$-catalyzed addition of dimethyl malonate to cyclopentadienyl acetate with catalysts selected from two series of 96 -and 40-member peptide libraries, this group also addressed the relevance of the secondary conformation of the peptide to the stereoselectivity of the catalytic process. They found that $\beta$-turns are better than helical conformations, and that occasionally the direct screening of the catalysts anchored on the solid support where they have been synthesized is possible with results comparable with those obtained in homogeneous solution.

If catalysis has proven an excellent proving ground for testing the potential of (pseudo)peptides a newly emerging application as fluorescent markers has been reported by Imperiali's group. Previously they had focused their research on peptidebased fluorescent chemosensors for $\mathrm{Zn}^{\mathrm{II}}$ [127]. Now the scope of their research has 
widened to the discovery of an $\mathrm{Ln}^{\mathrm{III}}$-binding peptide for rapid fluorescence detection of tagged proteins. The development of fluorescent proteins as molecular tags may enable complex biochemical processes to be correlated with the functioning in living cells [128]. The work by Imperiali is based on previous studies by other laboratories that had focused on sequences based on specific loops of calcium-binding proteins [129] for similarities in ionic radii and coordination preferences of $\mathrm{Ca}^{2+}$ and $\mathrm{Ln}^{3+}$ ions. This previous work [130] had pinpointed hot positions relevant both for binding and fluorescence enhancement in 14-mer peptides. Imperiali's screening [131] of a large (up to 500,000 member) library of peptides of the general sequence: Ac-Gly-Xaa-Zaa-Xaa-Zaa-Xaa-Gly-Trp-Zaa-Glu-Zaa-Zaa-Glu-Leu (where Xaa were varied between potential metal-binding residues Asp, Asn, Ser, or Glu and Zaa were hydrophobic amino acids) led to the discovery of a peptide with $K_{\mathrm{D}}$ for $\mathrm{Tb}^{3+}$ ions as low as $0.22 \mu \mathrm{M}$. They suggested that these lanthanide-binding tags (LBT) might constitute a new alternative for expressing fluorescent fusion proteins by routine molecular biological techniques. To find sequences with even better binding ability for this lanthanide ion they also devised a powerful combinatorial screening [132] on beads. The methodology utilizes solid-phase split-and-pool combinatorial peptide synthesis where orthogonally cleavable linkers provide the handle for an efficient two-step screening procedure (Fig. 1.27). The initial screening avoids the interference caused by on-bead screening by photochemically releasing a portion of the peptides into an agarose matrix for evaluation. The secondary screening further characterizes each hit in a defined aqueous solution. It is worth mentioning that this procedure
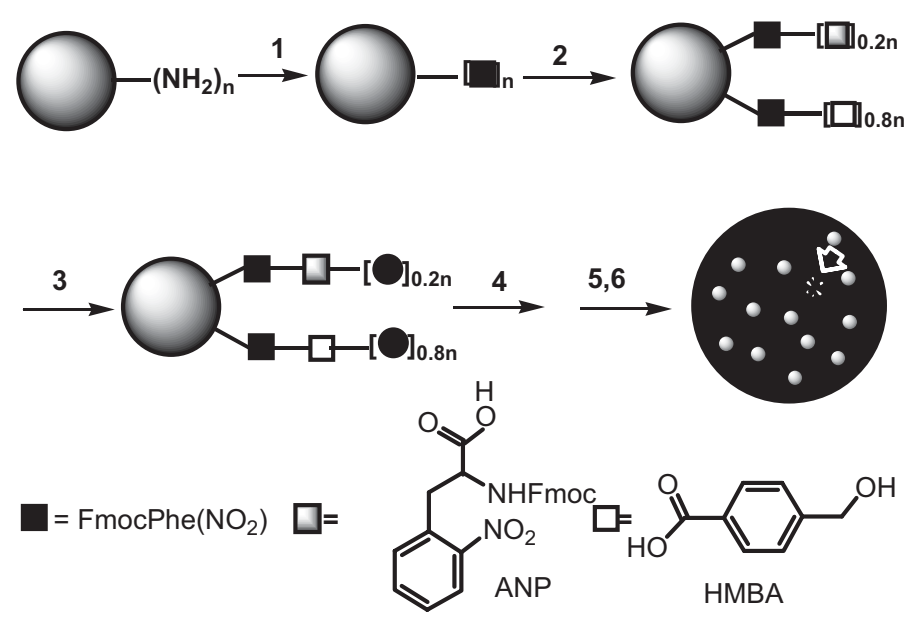

$=\beta$ AlaArgProGly - Fmoc

Figure 1.27 Imperiali's procedure for synthesis and screening of $\mathrm{Tb}^{3+}$-binding peptides:

1. Coupling of $N$ - $\alpha$-Fmoc-4-nitrophenylalanine.

2. Coupling of ANP:HMBA (1:10). 3. Introduction of the spacer sequence. 4. Synthesis of a "split-and-pool" library with a mass spectral ladder. 5, 6. Amino acid side-chain deprotection followed by casting into agarose with $50 \mu \mathrm{M} \mathrm{Tb^{3+ }}$ and photolysis. After selection of the beads with luminescent halos and work-up they are titrated with $\mathrm{Tb}^{3+}$ and the sequence deconvoluted by MALDI-MS. 
avoids interference from the solid support, in contrast with on-bead screening recently reported by Miller [133] and Davis [134] in which they look for products of a reaction produced by a solid-supported catalyst.

Long-lived proteins are susceptible to nonenzymatic chemical reactions and the evolution of fluorescence; little is known about the sequence-dependence of fluorogenesis, however. To address this point Van Vranken et al. [135] synthesized a library of over half a million octapeptides and exposed it to light and air in pH 7.4 buffer to identify fluorogenic peptides that evolve under mild oxidative conditions. The bead-based peptide library was composed of the general sequence $\mathrm{H}_{2} \mathrm{~N}-\mathrm{Ala}-(\mathrm{Xxx})_{6}$-Ala-resin, where $\mathrm{Xxx}$ was one of nine representative amino acids: Asp, Gly, His, Leu, Lys, Pro, Ser, Trp, and Tyr. Next, they selected five highly fluorescent beads from the library and subjected them to microsequencing, revealing the sequence of the unreacted peptide. All five fluorogenic sequences were ionic; lacked Tyr, His, and Leu; and most of the sequences contained only one Trp. Synthesis of the five soluble peptides revealed that one peptide $\left(\mathrm{H}_{2} \mathrm{~N}-\right.$ AlaLysProTrpGlyGlyAspAla$\mathrm{CONH}_{2}$ ) evolved into a highly fluorescent photoproduct and a nonfluorescent monooxygenated photoproduct. Their work demonstrated that peptide fluorogenesis depends on sequence and not merely on the presence of tryptophan. The potential importance of fluorogenic peptide sequences is twofold. First, fluorogenic sequences that arise by mutation might prove to be hot spots for human aging. Second, fluorogenic sequences, particularly those compatible with intracellular conditions, might serve as fluorescent tags (see above) for proteins or as fluorescent biomaterials.

\section{5}

\section{Conclusions}

We hope that this chapter (and the others in this book) will give the readers the flavor of what is brewing in the pot of scientists using peptides and pseudo-peptides in general for the synthesis of new supramolecules expanding the scope of the systems naturally available. This is an open-ended chapter, because research in this field is developing rapidly and new breakthroughs emerge almost every day. Particularly fascinating is the design of new foldamers because, as we have seen in many examples, conformational control constitutes a tremendous challenge rewarded by improved efficiency. Although the ability to predict conformation using $\alpha$-amino acids in very short sequences has improved considerably as the result of the seminal work done by Toniolo and his group, scientists are introducing new building blocks ( $\beta$ - and $\gamma$-amino acids for instance) [136] thus expanding the repertoire of accessible foldamers. These molecules, in contrast with standard peptides, might not be cleaved by proteins and, hence, are excellent candidates for new drugs.

The most fascinating field is that of the preparation of "smart" materials by conjugation of (pseudo)peptides and nanosystems such as nanoparticles or dendrimers. The possibility of controlling the structure of these systems at the molecular level (referred to as the "bottom up" approach in their preparation) constitutes an entry to complex molecular architectures with the possibility of defining specific functions. 
New fresh ideas will certainly contribute to give further momentum to the development of new supramolecules with improved efficiency.

\section{References}

1 M.L. Kopka, C. Yoon, D. Goodsell, P. Pjura, R.E. Dickerson Proc. Natl. Acad. Sci. USA. 1985, 82, 1376-1380.

2 M. Coll, C.A. Frederick, A.H.J. Wang, A. Rich Proc. Natl. Acad. Sci. USA 1987, 84, 8385-8389.

3 J.G. Pelton, D.E. Wemmer Proc. Natl. Acad. Sci. USA 1989, 86, 5723-5727.

4 P.B. Dervan Science 1986, 232, 464-471.

5 For reviews see: P.B. Dervan, B.S. Edelson Curr. Opin. Struct. Biol. 2003, 13, 284-299. P.B. Dervan Bioorg. Med. Chem. 2001, 9, 2215-2235.

6 S. White, J.W. Szewczyk, J.M. Turner, E.E. Baird, P.B. Dervan Nature, 1998, 391, 468-471.

7 C.L. Kielkopf, S. White, J.W. Szewczyk, J.M. Turner, E.E. Baird, P.B. Dervan, D.C. Rees Science, 1998, 282, 111-115.

8 M.A. Marques, R.M. Doss, A.R. Urbach, P.B. Dervan Helv. Chim. Acta 2002, 85, 4485-4517.

9 D. Renneberg, P.B. Dervan J. Am. Chem. Soc. 2003, 125, 5707-5716.

10 C.A. Briehn, P. Weyermann, P.B. Dervan Chem. Eur. J. 2003, 9, 2110-2122.

11 J.W. Trauger, E.E. Baird, P.B. Dervan Nature 1996, 382, 559-561.

12 D.M. Herman, J.M. Turner, E.E. Baird, P.B. Dervan J. Am. Chem. Soc. 1999, 121, 1121-1129.

13 B. Olenyuk, C. Jitianu, P.B. Dervan J. Am. Chem. Soc. 2003, 125, 4741-4751.

14 A. Heckel, P.B. Dervan Chem. Eur. J. 2003, 9, 1-14.

15 S.S. Swalley, E.E. Baird, P.B. Dervan Chem. Eur. J. 1997, 3, 1600-1607.

16 J.W. Trauger, E.E. Baird, P.B. Dervan Angew. Chem. Int. Ed. 1998, 37, 1421-1423.

17 D.M. Herman, E.E. Baird, P.B. Dervan Chem. Eur. J. 1999, 5, 975-983.

18 V.C. Rucker, S. Foister, C. Melander, P.B. Dervan J. Am. Chem. Soc. 2003, 125, 1195-1202.

19 K. Maeshima, S. Janssen, U.K. Laemmli EMBO J. 2001, 20, 3218-3228.

20 J.M. Belitzky, S.J. Leslie, P.S. Arora, T.A. Beerman, P.B. Dervan Bioorg. Med. Chem. 2002, 10, 3313-3318.

21 M.P. Gygi, M.D. Ferguson, H.C. Mefford, K.P. Lund, C. O’Day, P. Zhou, C. Friedman, G. Van den Engh, M.L. Stolowitz, B.J. Trask Nucleic Acids Res. 2002, 30, 2790-2799.

22 N.R. Wurtz, P.B. Dervan Chem. Biol. 2000, 7, 153-161.

23 L.A. Dickinson, R.J. Gulizia, J.W. Trauger, E.E. Baird, D.E. Mosier, J.M. Gottesfeld, P.B. Dervan Proc. Natl. Acad. Sci. USA. 1998, 95, 12890-12895.

24 E.J. Fechter, P.B. Dervan J. Am. Chem. Soc. 2003, 125, 8476-8485.

25 L.A. Dickinson, J.W. Trauger, E.E. Baird, P. Ghazal, P.B. Dervan, J.M. Gottesfeld Biochemistry, 1999, 38, 10801-10807.

26 A.K. Mapp, A.Z. Ansari, M. Ptashne, P.B. Dervan Proc. Natl. Acad. Sci. USA 2000, 97, 3930-3935.

27 A.Z. Ansari, A.K. Mapp, D.H. Nguyen, P.B. Dervan Chem. Biol. 2001, 8, 583-592.

28 P.S. Arora, A.Z. Ansari, T.P. Best, M. Ptashne, P.B. Dervan J. Am. Chem. Soc. 2002, 124, 13067-13071.

29 H.-D. Arndt, K.E. Hauschild, D.P. Sullivan, K. Lake, P.B. Dervan, A.Z. Ansari J. Am. Chem. Soc. 2003, 125, 13322-13323.

30 S. Janssen, O. Cuvier, M. Muller, U.K. Laemmli Mol. Cell. 2000, 6, 1013-1024.

31 B.S. Edelson, T.P. Best, B. Olenyuk, N.G. Nickols, R.M. Doss, S. Foister, A. Heckel, P.B. Dervan Nucleic Acids Res. 2004, 32, 2802-2818.

32 G. Wang, X.X.S. Xu Cell. Res. 2004, 14, 111-116.

33 M.C. De Koning, G.A. Van der Marel, M. Overhand Curr. Opin. Chem. Biol. 2003, 7, 734-740.

34 M. Pooga, T. Land, T. Bartfai, U. Langel Biomol. Eng. 2001, 17, 183-192.

35 P.E. Nielsen Acc. Chem. Res. 1999, 32, 624-630.

36 P.E. Nielsen, M. Egholm, R.H. Berg, O. Buchardt Science, 1991, 254, 1497-1500. 
37 S. Jordan, C. Schwemler, W. Kosch, A. Kretschmer, U. Stropp, E. Schwenner, B. Mielke Bioorg. Med. Chem. Lett. 1997, 7, 687-690.

38 M. D'Costa, V.A. Kumar, K.N. Ganesh Org. Lett. 2001, 3, 1281-1284.

39 M. Egholm, O. Buchardt, L. Christensen, C. Behrens, S.M. Freier, D.A. Driver, R.H. Berg, S.K. Kim, B. Norden, P.E. Nielsen Nature, 1993, 365, 566-568.

40 D.Y. Cherny, B.P. Belotserkovskii, M.D. Frank-Kamenetskii, M. Egholm, O. Buchardt, R.H. Berg, P.E. Nielsen Proc. Natl. Acad. Sci. USA 1993, 90, 1667-1670

41 Y.N. Kosaganov, D.A. Stetsenko, E.N. Lubyako, N.P. Kvitko, Y.S. Lazurkin, P.E. Nielsen Biochemistry, 2000, 39, 11742-11747.

42 H.J. Larsen, P.E. Nielsen Nucleic Acids Res. 1996, 24, 458-463.

43 T. Bentin, P.E. Nielsen Biochemistry 1996, 35, 8863-8869.

44 T. Bentin, P.E. Nielsen J. Am. Chem. Soc. 2003, 125, 6378-6379.

45 X. Zhang, T. Ishihara, D.R. Corey Nucleic Acids. Res. 2000, 28, 3332-3338.

46 U. Koppelhus, P.E. Nielsen Adv. Drug. Deliv. Rev. 2003, 55, 267-280.

47 R.W. Taylor, P.F. Chinnery, D.M. Turnbull, R.N. Lightowlers Nat. Genet. 1997, 15, 212-215.

48 J.C. Hanvey, N.J. Peffer, J.E. Bisi, S.A. Thomson, R. Cadilla, J.A. Josey Science, 1992, 258, 1481-1485.

49 G. Wang; K. Jing; R. Balczon; X. Xu J. Mol. Biol. 2001, 313, 933-940.

50 B. Liu; Y. Han, D.R. Corey, T. Kodadek J. Am. Chem. Soc. 2002, 124, 1838-1839.

51 B. Liu, Y. Han, A. Ferdous, D.R. Corey, T. Kodadek Chem. Biol. 2003, 10, 909-916.

52 B.M. Tyler, D.J. McCormick, C.V. Hoshall, C.L. Douglas, K. Jansen, B.W. Lacy, B. Cusack, E. Richelson FEBS Lett. 1998, 421 280-284.

53 B.M. Tyler, K. Jansen, D.J. McCormick, C.L. Douglas, M. Boules, J.A. Stewart, L. Zhao, B. Lacy, B. Cusack, A. Fauq, E. Richelson Proc. Natl. Acad. Sci. USA 1999, 96, 7053-7058.

54 J.C. Hanvey, N.J. Peffer, J.E. Bisi, S.A. Thomson, R. Cadilla, J.A. Josey, D.J. Ricca, C.F. Hassman, M.A. Bonham, K.G. Au, S.G. Carter, D.A. Bruckenstein, A.L. Boyd,
S.A. Noble, L.E. Babiss Science, 1992, 258 1481-1485.

55 H. Knudsen, P.E. Nielsen Nucleic Acids. Res. 1996, 24, 494-500.

56 P. Sazani, F. Gemignani, S.-H. Kang, M.A. Maier, M. Manoharan, M. Persmark, D. Bortner, R. Kole Nat. Biotech. 2002, 20, 1228-1233.

57 T. Berg Angew. Chem. Int. Ed. 2003, 42, 2462-2481.

58 M.W. Peczuh, A.D. Hamilton Chem. Rev. 2000, 100, 2479-2494.

59 R. Zutshi, M. Brickner, J. Chmielewski Curr. Opin. Chem. Biol. 1998, 2, 62-66.

60 T. Clackson, J.A. Wells Science, 1995, 267, 383-386.

61 A.A. Bogan, K.S. Thorn J. Mol. Biol. 1998, 280, 1-9.

62 A. Wlodawer, A. Miller, M. Jaskolski, B. Sathyanarayana, E. Baldwin, I. Weber, L. Selk, L. Clawson; J. Schneider, S. Kent Science, 1989, 245, 616-621.

63 R. Zutshi, J. Franciskovich, M. Shultz, B. Schweitzer, P. Bishop, M. Wilson, J. Chmielewski J. Am. Chem. Soc. 1997, 119, 4841-4845.

64 M.D. Shultz, M.J. Bowman, Y.-W. Ham, X. Zhao, G. Tora, J. Chmielewski Angew. Chem. Int. Ed. 2000, 39, 2710-2713.

65 S. Valente, M. Gobbo, G. Licini, A. Scarso, P. Scrimin Angew. Chem. Int. Ed. 2001, 40, 3899-3902.

66 P.H. Kussie, S. Gorina, V. Marechal, B. Elenbaas, J. Moreau, A.J. Levine, N.P. Pavletich Science, 1996, 274, 948-953.

67 C. García-Echeverría, P. Chène, M.J.J. Blommers, P. Furet J. Med. Chem. 2000, 43, 3205-3208.

68 Y. Hamuro, M. Crego Calama, H.S. Park, A.D. Hamilton Angew. Chem. Int. Ed. 1997, 36, 2680-2683.

69 Y. Wei, G.L. McLendon, A.D. Hamilton, M.A. Case, C.B. Purring, Q. Lin, H.S. Park, C.-S. Lee, T. Yu Chem. Commun. 2001, 1580-1581.

70 H.S. Park, Q. Lin, A.D. Hamilton J. Am. Chem. Soc. 1999, 121, 8-13.

71 (a) N. Voyer Top. Curr. Chem. 1996, 184, 1-37; (b) N. Voyer, J. Lamothe Tetrahedron 1995, 51, 9241-9284.

72 (a) S.H. Gellman Acc. Chem. Res. 1998, 31, 173-180; (b) D.J. Hill, M.J. Mio, R.B. Prince, T.S. Hughes, J.S. Moore Chem. Rev. 2001, 101, 3893-4011. 
73 Recent reviews: (a) L. Baltzer, H. Nilsson, J. Nilsson Chem. Rev. 2001, 101, 3153-3163; (b) L. Baltzer, J. Nilsson Curr. Opin. Chem. Biol. 2001, 12, 355-360; (c) R.B. Hill, D.P. Raleigh, A. Lombardi, W.F. DeGrado Acc. Chem. Res. 2000, 33, 745; (d) L. Baltzer, K.S. Broo Biopolymers, 1998, 31-40.

74 (a) R.G. Daugherty, T. Wasowicz, B.R. Gibney, V.J. DeRose Inorg. Chem. 2002, 41, 2623-2632; (b) G. Xing, V.J. DeRose Curr. Opin. Chem. Biol. 2001, 5, 196-200.

75 (a) J.R. Calhoum, H. Kono, S. Lahr, W. Wang, W.F. DeGrado, J.G. Saven J. Mol. Biol. 2003, 334, 1101-1115; (b) G. Maglio, F. Nastri, V. Pavone, A. Lombardi, W.F. DeGrado Proc. Natl. Acad. Sci USA 2003, 100, 3772-3777; (c) W.F. DeGrado, L. Di Costanzo, S. Geremia, A. Lombardi, V. Pavone, L. Randaccio Angew. Chem. Int. Ed. 2003, 42, 417-422; (d) E.N.G. Marsh, W.F. DeGrado Proc. Natl. Acad. Sci USA 2002, 99, 5150-5154; (e) L. Di Costanzo, H. Wade, S. Geremia, L. Randaccio, V. Pavone, W.F. DeGrado, A. Lombardi J. Am. Chem. Soc. 2001, 123, 12749-12757;

(f) J. Venkatraman, G.A. Naganawda, R. Sudha, P. Balaram Chem. Commun. 2001, 2660-2661.

76 K. Jonsson, R.K. Allemann, H. Widmer, S.A. Benner Nature 1993, 365, 530-532.

77 S. Olofsson, G. Johansson, L. Baltzer J. Chem. Soc., Perkin Trans 21995 , 2047-2056.

78 (a) J. Nilsson, L. Baltzer Chem. Eur. J. 2000, 6, 2214-2221; (b) L. Baltzer, K.S. Broo, H. Nilsson, J. Nilsson Bioorg. Med. Chem. 1999, 7, 83-91; (c) K.S. Broo, H. Nilsson, J. Nilsson, L. Baltzer J. Am. Chem. Soc. 1998, 120, 10287-10295.

79 (a) L.K. Anderson, G.T. Dolphin, L. Baltzer ChemBioChem 2002, 3, 741-751; (b) L.K. Andersson, G.T. Dolphin, J. Kihlberg, L. Baltzer J. Chem. Soc. Perkin Trans. 22000 , 459-464.

80 L.K. Andersson, M. Caspersson, L. Baltzer Chem. Eur. J. 2002, 8, 3687-3697.

81 M.A. Shogren-Knaak, B. Imperiali Bioorg. Med. Chem. 1999, 7, 1993-2002.

82 (a) M.P. Fitzsimons, J.K. Barton, J. Am. Chem. Soc. 1997, 119, 3379-3380; (b) K.D. Copeland, M.P. Fitzimons, R.P. Houser, J.K. Barton, Biochemistry 2002, 41, 343-356.

83 H. Ishida, Y. Inoue Rev. Heteroatom Chem. 1999, 19, 79-142.
84 P. Rossi, F. Felluga, P. Scrimin, Tetrahedron Lett. 1998, 39, 7159-7162.

85 P. Rossi, F. Felluga, P. Tecilla, L. Baltzer, P. Scrimin, Chem. Eur. J. , 2004, 10, 4163-4170.

86 P. Rossi, F. Felluga, P. Tecilla, F. Formaggio, M. Crisma, C. Toniolo, P. Scrimin Biopolymers 2000, 55, 496-501.

87 (a) P. Rossi, F. Felluga, P. Tecilla, F. Formaggio, M. Crisma, C. Toniolo, P. Scrimin J. Am. Chem. Soc. 1999, 121, 6948-6949; (b) C. Sissi, P. Rossi, F. Felluga, F. Formaggio, M. Palumbo, P. Tecilla, C. Toniolo, P. Scrimin J. Am. Chem. Soc. 2001, 123, 3169-3170.

88 A. Scarso, U. Scheffer, M. Göbel, Q.B. Broxterman, B. Kaptein, F. Formaggio, C. Toniolo, P. Scrimin Proc. Natl. Acad. Sci. USA 2002, 99, 5144-5149.

89 (a) A.J. Kennan, V. Haridas, K. Severin, D.H. Lee, M.R. Ghadiri J. Am. Chem. Soc. 2001, 123, 1797-1803; (b) A. Sghatelian, Y. Yokobayashi, K. Soltani, M.R. Ghadiri Nature, 2001, 409, 797-801; (c) K. Severin, D.H. Lee, J.A. Martinez, M. Veithm M.R. Ghadiri Angew. Chem. Int. Ed. Engl. 1998, 37, 126-128; (d) D.H. Lee, K. Severin, Y. Yokobayashi, M.R. Ghadiri Nature 1997, 390, 591-594; (e) D.H. Lee, J.R. Granja, J.A. Martinez, K. Severin, M.R. Ghadiri Nature 1996, 382, 525-528.

90 (a) X.Q. Li, J. Chmielewski J. Am. Chem. Soc. 2003, 125, 11820-11821; (b) X.Q. Li, J. Chmielewski Org. Biomol. Chem. 2003, 1, 901-904; (c) R. Issac, J. Chmielewski J. Am. Chem. Soc. 2002, 124, 6808-6809; (d) R. Issac, Y.W. Ham, J. Chmielewski Curr. Opin. Struct. Biol. 2001, 11, 458-463; (e) S. Yao,

I. Ghosh, R. Zutshi, J. Chmielewski Nature 1998, 396, 447-450; (f) S. Yao, I. Ghosh, R. Zutshi, J. Chmielewski Angew. Chem. Int. Ed. 1998, 37, 478-481; (g) S. Yao, I. Ghosh, R. Zutshi, J. Chmielewski J. Am. Chem. Soc. 1997, 119, 10559-10560.

91 F.H. Crick Acta Crystallogr. 1953, 6, 689-695.

92 P.B. Harbury, J.J. Plecs, B. Tidor, T. Alber, P.S. Kim Science 1998, 282, 1462-1467.

93 P.E. Dawson, T.W. Muir, I. Clark-Lewis, S.B.H. Kent Science 1994, 266, 776-779.

94 D.B. Smithrud, P.A. Benkovic, S.J. Benkovic, M. Taylor, K.M. Yager, J. Witherington, B.W. Philips, P.A. Spen- 
geler, A.B. Smith III, R. Hirschmann Proc. Natl. Acad. Sci USA 2000, 97, 1953-1958.

95 The "guru" of self-replication and of the treatment of the data of self-replicating systems is von Kiedrowski: G. von Kiedrowski Bioorg. Chem. Front 1993, 3, 113-118; A. Luther, R. Brandsch, G. von Kiedrowski Nature 1998, 396, 245-248.

96 A single recent review: A. Tossi, L. Sandri, A. Giangaspero Biopolymers 2000, 55, 4-30.

97 (a) M.R. Ghadiri Biopolymers 2003, 71, L21; (b) J. Sanchez-Ouesada, M.P. Isler, M.R. Ghadiri J. Am. Chem. Soc. 2002, 124, 10004-10005; (c) D.T. Bong, M.R. Ghadiri Angew. Chem. Int. Ed. 2001, 40, 2163-2166; (d) D.T. Bong J.D. Hartgerink, T.D. Clark, M.R. Ghadiri Chem. Eur. J. 1998, 4, 1367-1372; (e) T.D. Clark, J.M. Buriak, K. Kobayashi, M.P. Isler, D.E. McRee, M.R. Ghadiri J. Am. Chem. Soc. 1998, 120, 8949-8962; (f) H.S. Kim, J.D. Hartgerink, M.R. Ghadiri J. Am. Chem. Soc. 1998, 120, 4417-4424; (g) J.D. Hartgerink, J.R. Granja, R.A. Milligan, M.R. Ghadiri J. Am. Chem. Soc. 1996, 118, 43-50.

98 S. Fernandez-Lopez, H.S. Kim, E.C. Choi, M. Delgado, J.R. Granja, A. Khasanov, K. Ktaehenbuehl, G. Long, D.A. Weinberger, K.M. Wilcoxen, M.R. Ghadiri Nature 2001, 412, 452-455

99 J. Sanchez-Quesada, H.S. Kim, M.R. Ghadiri Angew. Chem. Int. Ed. 2001, 40, 2503-2507.

100 (a) E. Biron, F. Otis, J.-C. Meillon, M. Robitaille, J. Lamothe, P. Van Hove, M.-E. Cormier, N. Voyer Bioorg. Med. Chem. 2004, 12, 1279-1290; (b) Y.R. Vandenburg, B.D. Smith, E. Biron, N. Voyer Chem. Commun. 2002, 1694-1695; (c) J.-C. Meillon, N. Voyer, E. Biron, F. Sanschagrin, J.F. Stoddart Angew. Chem. Int. Ed. 2000, 39, 143-147; (d) N. Voyer, B. Guerin Chem. Commun. 1997, 2329-2331; (e) N. Voyer, M. Robitaille J. Am. Chem. Soc. 1995, 117, 6599-6600; (f) Voyer, N. J. Am. Chem. Soc. 1991, 113, 1818-1821.

101 (a) B. Baumeister and S. Matile, Chem. Eur. J. , 2000, 6, 1739-1749; (b) B. Baumeister, N. Sakai and S. Matile, Angew. Chem. Int. Ed. , 2000, 39, 1955-1959; (c) N. Sakai, B. Baumeister and S. Matile, ChemBioChem, 2000, 1, 123-125.

102 (a) P. Scrimin, A. Veronese, P. Tecilla, U. Tonellato, V. Monaco, F. Formaggio, M. Crisma, C. Toniolo J. Am. Chem. Soc. 1996, 118, 2505-2506; (b) P. Scrimin, P. Tecilla, U. Tonellato, A. Veronese, M. Crisma, F. Formaggio, C. Toniolo Chem. Eur. J. 2002, 8, 2753-2763.

103 M. Brust, M. Walker, D. Bethell, D. Schiffrin, R. Whyman, R. J. Chem. Soc., Chem. Commun. 1994, 801-802.

104 P. Pengo, S. Polizzi, M. Battagliarin, L. Pasquato, P. Scrimin, P. J. Mater. Chem. 2003, 13, 2471-2478.

105 M. Mammen, S.-K. Choi, G.M. Whitesides Angew. Chem. Int. Ed. 1998, 37, 2754-2794.

106 F. Manea, F. Bodar Houillon, L. Pasquato, P Scrimin Angew. Chem. Int. Ed. 2004, 43, 6165-6169.

107 P. Pengo, L. Pasquato, P. Scrimin, P. submitted for publication.

108 P. Pengo, L. Pasquato, S. Moro, A. Brigo, F. Fogolari, Q.B. Broxterman, B. Kaptein, P. Scrimin Angew. Chem. Int. Ed. 2003, 42, 3388-3392.

109 P. Pengo, Q.B. Broxterman, B. Kaptein, L. Pasquato, P. Scrimin Langmuir 2003, 19, 2521-2524.

110 (a) A. Esposito, E. Delort, D. Lagnoux, F. Djojo, J.-L. Reymond Angew. Chem. Int. Ed. 2003, 42, 1381-1383; (b) D. Lagnoux, E. Delort, C. Douat-Casassus, A. Esposito, J.-L. Reymond Chem. Eur. J. 2004, 10, 1215-1226.

11 M. Zhou, D. Bentley, I. Ghosh J. Am. Chem. Soc. 2004, 126, 734-735.

112 D.A. Tomalia Adv. Mater. 1994, 6, 529-539.

113 B.E. Turk, L.C. Cantley, Curr. Opin. Chem. Biol. 2003, 7, 84-90.

114 (a) K.S. Griswold, S.J. Miller Tetrahedron 2003, 59, 8869-8875; (b) B.R. Sculimbrene, A.J. Morgan, S.J. Miller Chem. Commun. 2003, 1781-1785; (c) B.R. Sculimbrene, A.J. Morgan, S.J. Miller J. Am. Chem. Soc. 2002, 124, 11653-11656; (d) B.R. Sculimbrene, S.J. Miller J. Am. Chem. Soc. 2001, 123, 10125-10126.

115 (a) E.R. Jarvo, S.J. Miller Tetrahedron 2002, 58, 2481-2485; (b) G.T. Copeland, S.J. Miller J. Am. Chem. Soc. 2001, 123, 6496-6502; (c) E.R. Jorvo, G.T. 
Copeland, N. Papaioannou, P.J. Bonitatebus, Jr.; S.J. Miller J. Am. Chem. Soc. 1999, 121, 11638-11643; (d) S.J. Miller, G.T. Copeland, N. Papaioannou, T.E. Horstmann, E.M. Ruel J. Am. Chem. Soc. 1998, 120, 1629-1630.

116 M.B. Francis, E.N. Jacobsen, Angew. Chem. Int. Ed. 1999, 38, 937-941.

117 A. Berkessel, D.A. Hérault, Angew. Chem. Int. Ed. 1999, 38, 102-105.

118 X. Huang, M.E. Pieczko, E.C. Long, Biochemistry 1999, 38, 2160-2166.

119 K.D. Shimizu, B.M. Cole, C.A. Krueger, K.W. Kuntz, M.L. Snapper, A.H. Hoveyda, . Angew. Chem. Int. Ed. Engl. 1997, 36, 1703-1707 and references therein.

120 (a) C.A. Krueger, K.W. Kruntz, C.D. Dzierba, W.G. Wirschum, J.D. Gleason, M.L. Snapper, A.H. Hoveyda J. Am. Chem. Soc. 1999, 121, 4284-4285; (b) J.R. Porter, W.G. Wirschun, K.W. Kuntz, M.L. Snapper, A.H. Hoveyda J. Am. Chem. Soc. 2000, 122, 2657-2658.

121 H. Deng, M.P. Isler, M. Snapper, A.H. Hoveyda, Angew. Chem. Int. Ed. 2002, 41, 1009-1012.

122 J.R. Porter, J.F. Traverse, A.H. Hoveyda, M.L. Snapper J. Am. Chem. Soc. 2001, 123, 984-985.

123 (a) C.A. Luchaco-Cullis, H. Mizutani, K.E. Murphy, A.H. Hoveyda, Angew. Chem. Int. Ed. Engl. 2001, 40, 1456-1460; (b) S.J. Degrado, H. Mizutani, A.H. Hoveyda, J. Am. Chem. Soc. 2002, 124, 13362-13363.

124 S.J. Degrado, H. Mizutani, A.H. Hoveyda J. Am. Chem. Soc. 2001, 123, 755-756.
125 S.R. Gilbertson, S.E. Collibee, A. Agarkov J. Am. Chem. Soc. 2000, 122, 6522-6523.

126 S.R. Gilbertson, X. Wang Tetrahedron 1999, 55, 11609-11618 and references therein.

127 G.K. Walkup, B. Imperiali, J. Am. Chem. Soc. 1997, 119, 3443-3450.

128 J. Lippincott-Schwartz, G.H. Patterson, Science 2003, 300, 87-91.

129 For the use of EF-hand sequences as Ln(III)-based metallonucleases see: J.T. Welch, W.R. Kearney, S.J. Franklin Proc. Natl. Acad. Sci USA 2003, 100, 3725-3730 and references therein.

130 J.P. MacManus, C.W. Hogue, B.J. Marsden, M. Sikorska, A.G. Szabo, J. Biol. Chem. 1990, 10358-10366.

131 K.J. Franz, M. Nitz, B. Imperiali, ChemBioChem 2003, 4, 265-271.

132 M. Nitz, K.J. Franz, R.L. Maglathlin, B. Imperiali, ChemBioChem 2003, 4, 272-276.

133 R.F. Harris, A.J. Nation, G.T. Copeland, S.J. Miller, J. Am. Chem. Soc. 2000, 122, 11270-11271.

134 M. Müller, T.W. Mathers, A.P. Davis, Angew. Chem. Int. Ed. 2001, 40, 3813-3815.

135 G.L. Juskowiak, S.J. Stachel, P. Tivitmahaisoon, D.L. Van Vranken J. Am. Chem. Soc., 2004, 126, 550-556.

136 R.P. Cheng, S.H. Gellman, W.F. DeGrado Chem. Rev. 2001, 101, 3219-3232. 
